\title{
Asset Prices Under Short-Sale Constraints
}

\author{
Yang Bai, Eric C. Chang and Jiang Wang*
}

First draft: October 15, 2003. This draft: November 12, 2006

\begin{abstract}
In this paper, we study how short-sale constraints affect asset price and market efficiency. We consider a fully rational expectations equilibrium model, in which investors trade to share risk and to speculate on private information in the presence of short-sale constraints. Short-sale constraints limit both types of trades, and thus reduce the allocational and informational efficiency of the market. Limiting short sales driven by risk-sharing simply shifts the demand for the asset upwards and consequently its price. However, limiting short sales driven by private information increases the uncertainty about the asset as perceived by less informed investors, which reduces their demand for the asset. When this information effect dominates, short-sale constraints actually cause asset prices to decrease and price volatility to increase. Moreover, we show that short-sale constraints can give rise to discrete price drops accompanied by a sharp rise in volatility when prices fail to be informative and the uncertainty perceived by uninformed investors surges.
\end{abstract}

*Bai (yangbai@business.hku.hk) and Chang (ecchang@business.hku.hk) are from the School of Business, University of Hong Kong, and Wang (wangj@mit.edu) is from Sloan School of Management, MIT, CCFR and NBER. The authors thank Hong Liu, Kathy Yuan, and participants of the 12th Mitsui Symposium on Financial Markets, the 2006 China International Conference in Finance, and seminars at FEP, ISCTE, Renmin University, University of North Carolina, and Washington University at St. Louis. This research is supported in part by the Hong Kong Research Grants Council (RGC) Competitive Earmarked Research Grant Awards 2005-2006 (HKU7656/05H) and the Area of Excellence Scheme funded by RGC (AoE/H-05/99). 


\section{Introduction}

Neo-classical asset-pricing models rely on the assumption that market participants can buy, sell and short sell securities at no cost. In practice, short selling a security is not as straightforward as simple selling or buying. Various costs and legal and institutional restrictions impose constraints on short selling. ${ }^{1}$ Although short-sale constraints have been attributed as an important factor in determining asset prices (see Rubinstein (2004) for a recent survey), the nature and the significance of their impact remain inconclusive. ${ }^{2}$

It is commonly hypothesized that short-sale constraints cause overpricing. In an earlier paper, Miller (1977) argues that as short-sale constraints keep more pessimistic investors out of the market, prices tend to reflect a more optimistic valuation than they otherwise would. ${ }^{3}$ In a multi-period setting, Harrison and Kreps (1978) show that short-sale constraints can drive the price even above the valuation of the most optimistic investors based on their expectations of future payoffs. Nonetheless, whether short-sale constraints will always lead to overpricing is far from certain. Using a rational expectations model, Diamond and Verrecchia (1987) show that constraining short sales reduces the informational efficiency of prices but does not bias them upward. In this paper, we further demonstrate that under rational expectations, short-sale constraints can in fact cause asset prices to decrease, which is in contrast to popular perception. Moreover, we show that short-sale constraints can lead to discrete drops in prices in the absence of big news, accompanies by a surge in perceived uncertainty in the market

\footnotetext{
${ }^{1}$ Short sellers face numerous costs and restrictions in establishing and maintaining a short position in a security, including the frictional securities lending market, the additional collateral requirement (Federal Reserve Regulation T), the up-tick rule (Securities and Exchange Commission [SEC] Rule 10a-1), a higher tax rate on profits on short sales (which are treated as short-term capital gain), the risk of short squeeze, and others. See, for example, SEC Concept Release: Short Sales (1999) and Danielsen and Sorescu (2001). For some institutional investors, short selling is prohibited by their charters. Almazan et al. (2003) report that about $70 \%$ of mutual funds explicitly state (in Form N-SAR they file with the SEC) that they are not permitted to sell short. Trading in derivatives when available, such as options and futures, provide alternative ways to take a short position in a security. However, derivatives trading has its own costs and restrictions (see, for example, Ofek and Richardson (2003)). Although we focus on short-sale constraints in the stock market in this paper, their importance is recognized in other markets as well such as the fixed-income market. See, for example, Krishnamurthy (2002).

${ }^{2}$ The literature on the impact of short-sale constrains is extensive. Theoretical work include Allen, Morris, and Postlewaite (1993), Cao and Zhang (2002), Diamond and Verrecchia (1987), Duffie, Galeanu and Pedersen (2002), Harrison and Kreps (1978), Hong and Stein (2003), Jarrow (1980), Miller (1977), Scheinkman and Xiong (2003), and Yuan (2004). There is also a large body of empirical work, including Altken, Frino, McCorry and Swan (1998), Asquith, Pathak and Ritter (2005), Battalio and Schultz (2005), Chang, Cheng and Yu (2006), Chen, Hong and Stein (2002), Conrad (1989), Danielsen and Sorescu (2001), D'Avolio (2002), Dechow, Hutton, Meulbroek and Sloan (2001), Figlewski (1981), Figlewski and Webb (1993), Geczy, Musto, and Reed (2002), Jones and Lamont (2002), Lamont and Stein (2004), Meyhew and Mihov (2005), Nagel (2005), Ofek and Richardson (2003), Senchack and Starks (1993), and Seneca (1967).

${ }^{3}$ See also Jarrow (1980).
} 
and in price volatility, a phenomenon similar to what we observe during market crashes.

Previous analysis focuses on how investors' expectations of future payoffs affect asset prices and how short-sale constraints may influence the relation between investors' expectations and asset prices. It ignores how risk affects prices and how short-sale constraints influence the risk as perceived by investors. In fact, most of the previous work simply assume that marginal investors are risk neutral. ${ }^{4}$ To the extent that risk matters for asset prices, shortsale constraints also influence prices through their impact on investors' perceived risk about the fundamentals. In particular, when more informed investors with negative information are held out from the market by short-sale constraints, market prices become less informative about their information. Under rational expectations, less informative prices need not bias the expectations of less informed investors since they are fully aware of the possible negative information held by the constrained investors. But they do become less certain about what this information is. In other words, the loss of informational efficiency from short-sale constraints increases the risk as perceived by less informed investors. When investors are risk averse, the increase in risk causes the price to decrease. When the degree of information asymmetry is significant, short-sale constraints can lower asset prices.

We consider a rational expectations model in which investors trade in a competitive stock market for two distinctive motives, to share risk and to speculate on private information, and they are subject to short-sale constraints. In particular, investors are endowed with shares of the stock and certain non-traded asset. Since the payoffs of the non-traded asset and the stock are correlated, investors want to trade the stock in order to share the risk from their nontraded asset. In addition, we assume that some investors receive private information about the stock's future payoff. Thus, these more informed investors also want to trade on their private information. In such an economy, the market plays both an allocational role and an informational role, which allows us to examine how short-sale constraints affect the efficiency of the market in serving these two roles. Unlike in Miller (1977) and Diamond and Verrecchia (1987), which focus on only one of the two trading motives, in our model trades driven by both motives can influence prices. As a result, short-sale constraints can affect the stock price differently through the limit they impose on these two types of trades. By comparing the equilibria of the two economies - one with short-sale constraints and the other without, we

\footnotetext{
${ }^{4}$ See, for example, Diamond and Verrecchia (1987), Harrison and Kreps (1978), Hong and Stein (2003), and Scheinkman and Xiong (2002). Although Miller (1977) does not assume risk-neutrality, the risk as perceived by investors is exogenously given. Their asset demand is mainly driven by their expectations of future asset payoffs. Thus, risk only plays a secondary role in his analysis (see also Jarrow (1980)). The two exception are Cao and Zhang (2002) and Yuan (2004), who also allows risk to affect investors' asset demand as we do here.
} 
obtain intriguing results on how short-sale constraints influence the behavior of asset prices.

We start by considering allocational trades. Some investors, when endowed with large amount of risks from the non-traded asset, may desire to take on negative positions in the stock to hedge the non-traded risk. Constraining short sales will prevent them from doing so, and thus shifts the overall demand for the stock upwards. This has the simple effect of increasing the equilibrium stock price. This effect is in the spirit of Miller (1977). But in our setting, the trades are motivated by the risk-sharing needs of investors, not different beliefs, which persist even in a fully rational expectations setting. Next, we consider informational trades, which are driven by the private information of more informed investors. Constraining short sales will prevent certain trades from informed traders with bearish news. Limiting these trades reduces the amount of information contained in the demand of the asset and the resulting price. Despite the fact that this reduction in the information content is asymmetric between good news and bad news, it does not cause a bias in the uninformed investors' expectations as they fully account for such an asymmetry when using the information revealed by the price. This is the main intuition of Diamond and Verrecchia (1987). However, the reduction in the price's information content (thus the market's informational efficiency) does increase the uncertainty about the asset as perceived by the uninformed investors. This effect of short-sale constraints on the market's informational efficiency will in turn affect investors' allocational trades. In particular, being risk averse, the less informed investors will reduce their demand for the asset in response to this increase in uncertainty. Consequently, the equilibrium price decreases when short-sale constraints limit the informational trades.

Since short-sale constraints limit both types of trades, the net impact on price depends on which one of the two effects dominates. We show that when the informational efficiency of the market is severely reduced, short-sale constraints can actually decrease asset prices. Also, in the absence of information asymmetry, short-sale constraints reduces stock price volatility as they limit the range of fluctuations in aggregate stock demand. But in the presence of information asymmetry, short-sale constraints can cause the price volatility to increase as less informed investors perceive higher risks and demand larger price adjustments in accommodating trades.

In addition, we show that with short-sale constraints, the market price becomes uninformative in certain states when informed investors are completely held out from the market. Such a failure for the market price to provide information leads to a surge in uncertainty about asset payoffs as perceived by the less informed investors. As a result, the price drops discretely 
in these states and price volatility jumps up. Such a price behavior resembles what we observe during market crashes: Prices fall abruptly without big news; the price drop is accompanied by more confusion in the market rather than clarity about the state of the economy; and such an increase in confusion is reflected in the higher price volatility after a crash. Thus, our model implies that short-sale constraints can be a potential cause of market crashes.

Although several authors have considered links between short-sale constraints and market crashes (Hong and Stein (2003), Scheinkman and Xiong (2003) and Yuan (2004)), our results on market crashes are qualitatively different from theirs. In particular, in our model crashes arise from sudden increases in perceived uncertainty while earlier models associate crashes with revisions of expectations as more private information is incorporated into prices, which would be accompanied with decreases in perceived uncertainty and price volatility. The mechanism for market crashes in our model and its implications are more consistent with what we observe.

Our paper also makes a technical contribution. In essence, our "partial revealing equilibrium" model is an extension of Grossman-Stiglitz (1980)'s framework with differently informed investors. However, with short-sale constraints, solutions to investors' posterior beliefs, optimal holdings, and the resulting equilibrium price become highly nonlinear in the underlying state variables. The nonlinear nature of the problem makes a closed-form solution hard to obtain and the analysis difficult. Using set-ups similar to ours, Cao and Zhang (2002) and Yuan (2004) rely on numerical solutions to analyze short-sale constraints. By properly choosing the preference and distribution assumptions, we are able to solve the model in closed-form in the presence of short-sale constraints. Obtaining a closed-form solution allows us to obtain sharp results as well as clear understanding of the mechanism behind them.

The rest of this paper is organized as follows. Section 2 describes the basic model. Section 3 solves the equilibrium for a simple version of the model. Section 4 analyzes the impact of short-sale constraints on the behavior of asset prices. Section 5 considers the general solution to the model. Section 6 concludes. Proofs are in the appendix.

\section{The Model}

Our model attempts to capture two important features of the securities market: investor heterogeneity and short-sale constraints. Investors are heterogeneous in two dimensions, their risk-sharing needs and their private information about asset payoffs. They trade in the market either to share risk or to speculate on private information. However, they are constrained from short selling. 
For tractability and expositional clarity, we will keep parsimony in modelling the economic environment and the heterogeneity among investors. The economy is further defined as follows.

\subsection{Securities Market}

There are two dates, 0,1 . Two securities are traded in a competitive securities market, a risk-free security, which we call bond, and a risky security, which we call stock. A unit of the bond yields a sure payoff of 1 at date 1 and each share of the stock yields a risky payoff of $V$. As a random variable, $V$ consists of two additive components,

$$
V=F+u
$$

where $F$ and $u$ are both random variables with zero mean. We will use the risk-free bond as the numeraire and denote the price of the stock at date 0 by $P$.

\section{$2.2 \quad$ Investors}

There are two classes of investors - I-investors and U-investors. They are identical within each class but different between classes in terms of their information and risk-sharing needs. The population weight of I-investors is $w$, and that of $\mathrm{U}$-investor is $1-w$. For convenience, we denote each investor by $i$, where $i=I, U$.

\section{A Endowments}

Each investor $i(i=I, U)$ is initially endowed with zero amount of the bond and $\bar{\theta} \geq 0$ shares of the stock. In addition, he is also endowed with $X_{i}$ units of a non-traded asset. Each unit of the non-traded asset yields a payoff of $N$ at date 1 . We assume that $u$ and $N$ have a covariance of $\sigma_{u N}$. To fix ideas, we set $\sigma_{u N}$ to be positive. Thus, the risk from the non-traded asset is positively correlated with the risk of the stock. For simplicity, we further assume that $X_{I}, X_{U}$ and $N$ are random variables with zero mean.

The heterogeneity among investors in their endowments of the non-traded asset gives rise to their needs in trading to share risk. In particular, a large endowment in the non-traded asset makes an investor want to reduce his stock holdings in order to maintain an optimal overall risk profile, when the payoffs from the stock and the non-traded asset are positively correlated.

It is worth pointing out that introducing the non-tradable asset is merely a simple way to introduce investor heterogeneity in risk exposure, which then leads to their risk-sharing 
trades. ${ }^{5}$ Other forms of heterogeneity can be introduced to generate risk-sharing trades as well, such as heterogeneity in preferences (e.g., Dumas (1989) and Wang (1996)) and beliefs (e.g., Detemple and Murthy (1994), Miller (1977), and Harris and Raviv (1993)). We choose the current form of heterogeneity mainly for tractability.

\section{B Information}

At date 0 , each investor observes his own endowment of the non-traded asset $\left(X_{I}\right.$ or $\left.X_{U}\right)$. In addition, I-investors observe $F$ (their private information). Also, all investors observe the market price of the stock $P$. Thus, the information set of I-investors at date 0 is given by $\mathcal{I}_{I}=\left\{X_{I}, F, P\right\}$, and that of $\mathrm{U}$-investors is given by $\mathcal{I}_{U}=\left\{X_{U}, P\right\}$. At date 1 , all uncertainty is resolved. Since I-investors have private information about the stock's payoff while U-investors do not, we will also refer to them as informed and uninformed investors, respectively.

\section{Preferences}

Each investor is risk averse. For tractability, we assume that he has a Markowitz-Tobin mean-variance preference over his terminal wealth. Let $\theta_{i}$ denote the optimal stock holding of investor $i$ and $W_{i}$ his terminal wealth at date 1 . We have

$$
W_{i}=\bar{\theta} P+\theta_{i}(V-P)+X_{i} N, \quad i=I, U
$$

The preference of investor $i$ is given by

$$
\mathrm{E}\left[W_{i} \mid \mathcal{I}_{i}\right]-\frac{1}{2} \operatorname{Var}\left[W^{i} \mid \mathcal{I}_{i}\right], \quad i=I, U
$$

where $\mathcal{I}_{i}$ is investor $i$ 's information set, and $\mathrm{E}\left[\cdot \mid \mathcal{I}_{i}\right]$, $\operatorname{Var}\left[\cdot \mid \mathcal{I}_{i}\right]$ are the expectation and variance conditional on $\mathcal{I}_{i}$, respectively. ${ }^{6}$

\subsection{Short-Sale Constraints}

We assume that investors are subject to short-sale constraints. In particular, we assume that for investor $i(i=I, U)$, his stock position is bounded below by a non-positive number: $\theta_{i} \geq-b_{i}$, where $b_{i} \geq 0$. Here, for convenience, the short-sale constraint is assumed to be the

\footnotetext{
${ }^{5}$ Endowment shocks have been introduced as a risk-sharing motive to trade in various forms. See, for example, Grossman and Stiglitz (1980), Wang (1994), and O'Hara (2003). Our approach allows us to model the risk-sharing trades as investors' optimal behavior.

${ }^{6}$ Although widely used in both theoretical analysis and practice, mean-variance preferences do not meet some of the standard conditions imposed on preferences. We can choose instead a quadratic utility function for the investors and show that the results we obtain in the paper remain qualitatively the same. For simplicity in exposition, we use mean-variance preference which gives closed-form solutions.
} 
same for investors within the same class but can be different between the two classes. As our analysis later shows, this is immaterial. All we need is that some investors, especially some informed investors, are constrained. For $b_{i}>0$, investor $i$ is allowed to take a short position up to $b_{i}$. When $b_{i}=0$, no short position is allowed for investor $i$. The actual level of $b_{i}$ is not important for most of our qualitative results. Thus, in the analysis below, we set $b_{i}$ to zero when its actual level is not the focus.

\subsection{Distributional Assumptions}

For tractability, we assume specific distributions for the shocks to the economy. In particular, we assume that $F, u$ and $X_{I}, X_{U}$ are uniformly and independently distributed. Without loss of generality, we assume that $F, u, X_{I}$, and $X_{U}$ have the range of $\left[-a_{F}, a_{F}\right],\left[-a_{u}, a_{u}\right],\left[-a_{I}, a_{I}\right]$, and $\left[-a_{U}, a_{U}\right]$, respectively. Thus, their variances will be $\sigma_{F}^{2}=\frac{1}{3} a_{F}^{2}, \sigma_{u}^{2}=\frac{1}{3} a_{u}^{2}, \sigma_{I}^{2}=\frac{1}{3} a_{I}^{2}$, and $\sigma_{U}^{2}=\frac{1}{3}{a_{U}}^{2}$, respectively. In order to solve the model in closed-form, we need the following parameter restriction to obtain certain monotonicity property of the price function:

$$
\sigma_{u} \geq \sigma_{F} \geq 3 \sigma_{u N} \sigma_{U}
$$

To simplify exposition, we will limit ourselves to a specific set of parameter values. In particular, we let

$$
\sigma_{u N}=\sigma_{F} / \sigma_{I}
$$

Also, we will focus on the case in which $X_{U}=0$ (i.e., $\sigma_{U}=0$ ), $b_{U}=\infty$ and $b_{I}=0$. In other words, only I-investors have inherent trading needs and face short-sale constraints. This case allows us to obtain our main results without bearing unnecessary details.

The uniform distribution and the parameter restriction (4) are important for the closedform solution to the equilibrium. The other parameter restrictions are imposed mainly to simplify exposition and analysis. They do not affect the qualitative nature of our main results. We will return in Section 5 to the general solution of the model without imposing these parameter restrictions.

\section{The Equilibrium}

We now solve for the equilibrium of the economy defined in Section 2. The equilibrium concept we use is the standard one of rational expectations. In particular, in equilibrium investors 
maximize their expected utility:

$$
\begin{array}{cl}
\max _{\theta_{i} \geq-b_{i}} & \mathrm{E}\left[W_{i} \mid \mathcal{I}_{i}\right]-\frac{1}{2} \operatorname{Var}\left[W_{i} \mid \mathcal{I}_{i}\right], \quad i=I, U \\
\text { s.t. } & W_{i}=\bar{\theta} P+\theta_{i}(V-P)+X_{i} N
\end{array}
$$

and the market clears:

$$
w \theta_{I}+(1-w) \theta_{U}=\bar{\theta}
$$

Given the mean-variance preference, the following result is immediate:

LEMMA 1 Investor's optimal stock holding is as follows:

$$
\theta_{i}=\max \left[\frac{\left(\mathrm{E}\left[F \mid \mathcal{I}_{i}\right]-P\right)-\sigma_{u N} X_{i}}{\operatorname{Var}\left[F \mid \mathcal{I}_{i}\right]+\sigma_{u}^{2}}, \quad-b_{i}\right], \quad i=I, U .
$$

Each investor's stock demand clearly reflects his two trading motives: to share the risk from non-traded assets and to speculate on private information about future stock payoff. In the absence of information asymmetry, all investors perceive the same expectation and variance for the stock payoff, i.e., $\mathrm{E}\left[F \mid \mathcal{I}_{i}\right]$ and $\operatorname{Var}\left[F \mid \mathcal{I}_{i}\right]$. The only factor driving the difference in their demand, and thus trading between them, is their risk exposure through the non-traded asset $X_{i}$. In other words, they trade in the market to share this risk. In the presence of information asymmetry, however, investors perceive different expectations and variances for the stock payoff. Their stock holdings also depend on these perceptions. In addition, investors' demand is also bounded by short-sale constraints.

How short-sale constraints affect equilibrium prices heavily depends on the relative importance of these two types of trades. For this reason, we will first consider the simple case of symmetric information and then analyze the case of asymmetric information.

\subsection{Symmetric Information}

Suppose that $F, X_{I}$ and $X_{U}$ are all public information, i.e., $\mathcal{I}_{I}=\mathcal{I}_{U}=\left\{F, X_{I}, X_{U}, P\right\}$. Then, $\mathrm{E}\left[F \mid \mathcal{I}_{i}\right]=F$ and $\operatorname{Var}\left[F \mid \mathcal{I}_{i}\right]=0, i=I, U$. In this case, investors have homogenous information about the stock's payoff but heterogenous risk-sharing needs. So their only trading motive is to achieve the optimal risk-return trade-off. Let us first consider the case without short-sale constraints. This corresponds to letting $b_{i}=\infty$ for $i=I, U$. From (8) and (7), the equilibrium price at time 0 is

$$
P^{*}=F-w \sigma_{u N} X_{I}-\sigma_{u}^{2} \bar{\theta} .
$$


The economic meaning of the equilibrium price function is obvious. When $X_{I}=0$, the price simply equals the expected payoff, $F$, minus a risk premium, $\sigma_{u}^{2} \bar{\theta}$, which is proportional to the payoff variance of each stock share and the total the number of shares per capita. When $X_{I}$ is, say, positive, the I-investors are exposed to the additional risk from their non-traded assets. Since this risk is positively correlated with the risk from the stock, the I-investors will want to reduce their stock demand to optimize their overall portfolio, which includes both the stock and the non-traded asset. In particular, from (8) (with $b_{i}=\infty$ ), the drop in an I-investor's stock demand is $\left(\sigma_{u N} / \sigma_{u}^{2}\right) X_{I}$. The coefficient $h=\sigma_{u N} / \sigma_{u}^{2}$ can be interpreted as the hedge ratio, i.e., the number of shares an I-investor wants to short in order to hedge the risk from each unit of non-traded asset. The decrease in I-investors' demand for the stock causes its price to decrease by $w \sigma_{u N} X_{I}$, where $w$ is I-investors' population weight.

We next consider the case with short-sale constraints, but only for the I-investors. The equilibrium price becomes

$$
P= \begin{cases}F-w \sigma_{u N} X_{I}-\sigma_{u}^{2} \bar{\theta}, & X_{I} \leq \widehat{\theta} / h \\ F-\sigma_{u}^{2} \widehat{\theta}, & X_{I}>\widehat{\theta} / h\end{cases}
$$

where $\widehat{\theta}=\bar{\theta} /(1-w)$. We note that $\widehat{\theta}$ gives the stock shares each U-investor has to hold when all the I-investors are out of the market (i.e., hold no shares of the stock). Clearly, for $X_{I} \leq \widehat{\theta} / h$, the short-sale constraint is not binding for the I-investors and the equilibrium stock price has the same form as in the case without short-sale constraints given in (9). However, for $X_{I}>\widehat{\theta} / h$, the short-sale constraint is binding for the I-investors. In this case, the Uinvestors are holding all the shares, which is $\widehat{\theta}$ for each of them. The price simply becomes $P=F-\sigma_{u}^{2} \widehat{\theta}$.

In equilibrium, an I-investor's stock holding is given by

$$
\theta_{I}=\max \left[\left(F-P-\sigma_{u N} X_{I}\right) / \sigma_{u}^{2}, 0\right]=\max \left[\bar{\theta}-(1-w) h X_{I}, 0\right]
$$

Clearly, it is decreasing in $X_{I}$. The short-sale constraint is binding when $X_{I}>\bar{\theta} /[(1-w) h]$. Note that $X_{I}$ has an upper bound of $a_{I}$. Thus, $X_{I}>\bar{\theta} /[(1-w) h]$ is possible only if

$$
a_{I}>\frac{1}{h} \frac{\bar{\theta}}{1-w}
$$

Otherwise, $X_{I} \leq \bar{\theta} /[(1-w) h]$ always holds; thus, the short-sale constraint is never binding for the I-investors and we have the unconstrained equilibrium despite the presence of the constraint. Since we are interested in the situation when the short-sale constraint is binding, 
at least sometimes, we will assume that condition (11) is satisfied unless stated otherwise. Given (5), (11) also implies:

$$
a_{F}>\sigma_{u}^{2} \widehat{\theta}
$$

Comparing the equilibrium price with and without the short-sale constraint, we see that for $X_{I}<\widehat{\theta} / h, P=P^{*}$, and for $X_{I}>\widehat{\theta} / h, P>P^{*}$. Thus, we have the following result:

PROPOSITION 1 Under symmetric information, short-sale constraints always lead to an increase in the stock price, i.e., $P \geq P^{*}$.

The intuition behind this result is straightforward: Limiting some investors' holdings to be nonnegative effectively increases the total demand for the stock. In an economy with a downward sloping demand curve, it must drive equilibrium prices upward. This is the point of Miller (1977), which focuses the impact of short-sale constraints when investors trade for allocational reasons.

\subsection{Asymmetric Information without Short-Sale Constraints}

We now consider the case when investors are heterogenous in both their risk-sharing needs and information on stock payoff. Since the I-investors trade for both risk-sharing and private information, their trades will not fully reveal their information. Thus, information asymmetry between the two types of investors persists in equilibrium. This makes the solution to the equilibrium challenging, especially in the presence of short-sale constraints. We solve the equilibrium in three steps. First, we conjecture a particular form of the equilibrium price function. Next, we derive the stock demand of the informed and uninformed investors under the conjectured price function. Finally, we confirm that the market indeed clears under the conjectured price function, which then gives us a market equilibrium.

We start with the equilibrium without any short-sale constraints. Let $P^{*}$ denote the equilibrium stock price in this case, which in general depends on the underlying state variables of the economy. In our setting, the state variables include $F$, the information the informed investors have about stock payoff, and $X_{I}$, their holding of the non-traded asset. Ex ante, we expect $P^{*}$ to be a function of $F$ and $X_{I}$. But more specifically, we propose the following form on the price function:

CONJECTURE 1 When $\sigma_{U}=0$ and without short-sale constraints, the stock price depends only on $S=\frac{1}{2}\left(F-\sigma_{u N} X_{I}\right)$. Moreover, it is a strictly increasing function of $S$. 
We now solve for investors' stock demand under the conjectured price function. An informed investor's information set is $\mathcal{I}_{I}=\left\{F, X_{I}, P^{*}\right\}$. From (8) with $b_{I}=\infty$, we have

$$
\theta_{I}=\frac{F-\sigma_{u N} X_{I}-P^{*}}{\sigma_{u}^{2}}=\frac{2 S-P^{*}}{\sigma_{u}^{2}} .
$$

Apparently, the stock demand of the I-investors is linear in $S$ and the stock price $P^{*}$. Under the parameter restriction (5), the definition area of $S$ is $\left[-a_{F}, a_{F}\right]$.

An uninformed investor's information set is $\mathcal{I}_{U}=\left\{P^{*}\right\}$. He does not observe $F$ and $X_{I}$. But he can extract information about them from the market price. In particular, under the conjectured price function, $P^{*}$ reveals $S$, which is a linear function of $F$ and $X_{I}$. Thus, observing $P^{*}$ allows an uninformed investor to learn about $F$, although only imperfectly. In particular, $\mathrm{E}\left[\cdot \mid \mathcal{I}_{U}\right]=\mathrm{E}\left[\cdot \mid P^{*}\right]=\mathrm{E}[\cdot \mid S]$ and we have the following result:

LEMMA 2 Let $f(F \mid S)$ denote the probability density of $F$ conditional on $S$. Then,

$$
f(F \mid S)= \begin{cases}\frac{1}{2\left(a_{F}-S\right)} 1_{\left[-a_{F}+2 S, a_{F}\right]}(F), & S \geq 0 \\ \frac{1}{2\left(a_{F}+S\right)} 1_{\left[-a_{F}, a_{F}+2 S\right]}(F), & S<0\end{cases}
$$

where $1_{A}(x)$ is an indicator function, which equals 1 if $x \in A$ and 0 otherwise. Moreover, the first two moments of $F$ conditional on $S$ are:

$$
\mathrm{E}[F \mid S]=S, \quad \operatorname{Var}[F \mid S]=\frac{1}{3}\left(a_{F}-|S|\right)^{2}
$$

Clearly, the posterior distribution of $F$ conditional on $S$ remains uniform but is more precise than their prior information. Moreover, $S$ is simply the mean of $F$ conditional on $S$. In general, $\mathrm{E}[F \mid S]$ is a linear function of $S$, where the slope depends on the ratio between $\sigma_{u N}$ and $\sigma_{F} / \sigma_{I}$. Under the parameter restriction (5), we have the simple expression in (15).

Given their posterior belief about the underlying shocks based on the information from the stock price, U-investors' optimal demand for the stock is given in the following lemma:

LEMMA 3 Suppose that $P^{*}$ is a strictly increasing function of $S=\frac{1}{2}\left(F-\sigma_{u N} X_{I}\right)$. Without short-sale constraints, a U-investor's optimal stock demand is

$$
\theta_{U}=\frac{S-P^{*}}{\sigma_{u}^{2}+\frac{1}{3}\left(a_{F}-|S|\right)^{2}} .
$$

From Equations (13), (16) and the market-clearing condition (7), we can solve for the equilibrium price $P^{*}$ : 
PROPOSITION 2 When $\sigma_{U}=0$ and without short-sale constraints, the economy defined in Section 2 has a rational expectations equilibrium in which the stock price is given by

$$
P^{*}=2 S-\sigma_{u}^{2} \bar{\theta}-(1-w) \frac{S+\frac{1}{3}\left(a_{F}-|S|\right)^{2} \bar{\theta}}{1+\frac{1}{3} w\left(a_{F}-|S|\right)^{2} / \sigma_{u}^{2}} .
$$

Moreover, $P^{*}$ is a continuous and strictly increasing function of $S$.

Proposition 2 clearly confirms our conjecture about the form of the price function. Given the equilibrium price, we can compute investors' equilibrium holdings:

COROLLARY 1 When $\sigma_{U}=0$ and without short-sale constraints, $I$ - and U-investors' equilibrium stock holdings are given by

$$
\theta_{I}=\bar{\theta}+(1-w) \frac{S+\frac{1}{3}\left(a_{F}-|S|\right)^{2} \bar{\theta}}{\sigma_{u}^{2}+\frac{1}{3} w\left(a_{F}-|S|\right)^{2}}, \quad \theta_{U}=\bar{\theta}-w \frac{S+\frac{1}{3}\left(a_{F}-|S|\right)^{2} \bar{\theta}}{\sigma_{u}^{2}+\frac{1}{3} w\left(a_{F}-|S|\right)^{2}}
$$

respectively. Moreover, an I-investor's equilibrium stock holding is strictly increasing in $S$, and U-investor's is strictly decreasing in $S$.

Figure 1 illustrates investors' equilibrium stock holdings.

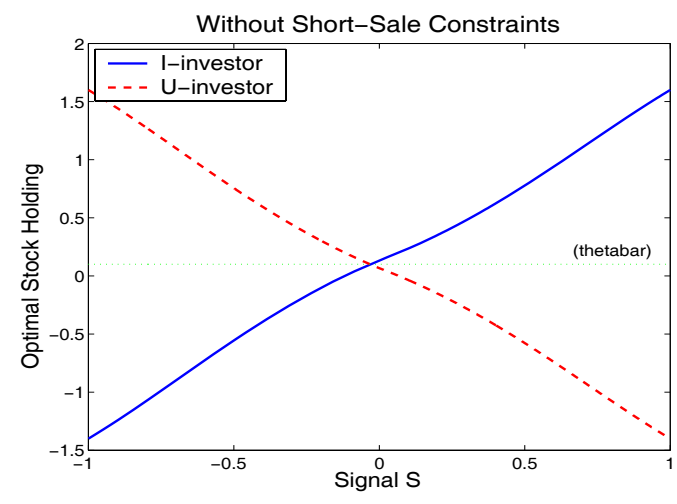

Figure 1: Investors' equilibrium stock holdings without short-sale constraints. The equilibrium stock holding of I-investors (the solid line) increases with signal $S=\frac{1}{2}\left(F-\sigma_{u N} X_{I}\right)$ while that of U-investors (dashed line) decreases with $S$. The parameter values are $a_{u}=a_{F}=$ $a_{I}=1, \bar{\theta}=0.1$, and $w=0.5$.

\subsection{Asymmetric Information with Short-Sale Constraints}

We now consider the case in which short selling is constrained. As before, we start by conjecturing the form of the price function and then confirm it with the solution of the equilibrium. 
CONJECTURE 2 When $\sigma_{U}=0$ and with short-sale constraints, the stock price, denoted by $P$, only depends on $S=\frac{1}{2}\left(F-\sigma_{u N} X_{I}\right)$. Moreover, it is a strictly increasing function of $S$ for $S>z$ and a constant for $S \leq z$, where $z$ is a negative constant.

We note that the price function in the presence of short-sale constraints is conjectured to be a weakly increasing function of $S$. It is strictly increasing in $S$ only for $S>z$ and remains constant for $S \leq z$. The conjectured form of $P$ is motivated by the following observation: When $S$ is sufficiently small, the I-investors' stock demand falls below zero for a range of prices. With short-sale constraints, they will be out of the market. As a result, the stock price will no longer reflect their demand and become independent of $S$. This possibility is captured by the constant segment of the price function when $S$ is below certain threshold $z$. Let $\widehat{p}$ denote the price at $S=z$.

We now derive the investors' demand for the stock under the conjectured price function. From Equation (8), I-investors' optimal demand for the stock is as follows:

$$
\theta_{I}=\max \left[(2 S-P) / \sigma_{u}^{2}, 0\right] \text {. }
$$

For the uniformed investors, the situation is more complex. We first need to compute their posterior distribution of $F$ conditional on $P$, which is given below.

LEMMA 4 Let $f(F \mid P)$ denote the probability density of $F$ conditional on $P$, which has the form in Conjecture 2. Then,

$$
f(F \mid P)= \begin{cases}f(F \mid S), & P>\widehat{p} \\ \frac{\left(2 z+a_{F}\right)-F}{2\left(z+a_{F}\right)^{2}} 1_{\left[-a_{F}, 2 z+a_{F}\right]}(F), & P \leq \widehat{p}\end{cases}
$$

where $f(F \mid S)$ is given in Lemma 2 and $z<0$ from Conjecture 2. Moreover, the first two moments of $F$ conditional on $P$ are:

$$
\mathrm{E}[F \mid P]=\left\{\begin{array}{ll}
S, & P>\widehat{p} \\
\frac{1}{3}\left(2 z-a_{F}\right), & P \leq \widehat{p}
\end{array}, \quad \operatorname{Var}[F \mid P]= \begin{cases}\frac{1}{3}\left(a_{F}-|S|\right)^{2}, & P>\widehat{p} \\
\frac{2}{9}\left(z+a_{F}\right)^{2}, & P \leq \widehat{p}\end{cases}\right.
$$

It is important to note that the mean and variance of $F$ conditional on market price are in general discontinuous at $P=\widehat{p}$. As we will see in Section 4 , the discontinuity in the Uinvestors' perception about the fundamental has important implications on the behavior of the market.

From the U-investors' posterior distribution of $F$ conditional on price, we can then derive their stock demand: 
LEMMA 5 If the price function has the form in Conjecture 2, then the U-investors demand for the stock is given by

$$
\theta_{U}= \begin{cases}\frac{S-P}{\sigma_{u}^{2}+\frac{1}{3}\left(a_{F}-|S|\right)^{2}}, & P>\widehat{p} \\ \frac{\frac{1}{3}\left(2 z-a_{F}\right)-P}{\sigma_{u}^{2}+\frac{2}{9}\left(z+a_{F}\right)^{2}}, & P \leq \widehat{p}\end{cases}
$$

where $\widehat{p}$ is the stock price at $S=z$.

Given the optimal stock demand of both classes of investors, we can now solve for the equilibrium. The result is given in the following proposition:

PROPOSITION 3 Suppose that $\sigma_{U}=0$ and investors face short-sale constraints. Let

$$
\begin{aligned}
z & =-a_{F}-3 \widehat{\theta}^{-1}+3 \sqrt{\widehat{\theta}^{-2}+\frac{1}{2} a_{F} \widehat{\theta}^{-1}-\frac{1}{2} \sigma_{u}^{2}} \\
z^{*} & =-a_{F}-\frac{3}{2} \widehat{\theta}^{-1}+\frac{3}{2} \sqrt{\widehat{\theta}^{-2}+\frac{4}{3} a_{F} \widehat{\theta}^{-1}-\frac{4}{3} \sigma_{u}^{2}}
\end{aligned}
$$

where $\widehat{\theta}=\bar{\theta} /(1-w)$. Then, $z \leq z^{*}<0$. The equilibrium stock price is given by

$$
P= \begin{cases}2 S-\sigma_{u}^{2} \bar{\theta}-(1-w) \frac{S+\frac{1}{3}\left(a_{F}-|S|\right)^{2} \bar{\theta}}{1+\frac{1}{3} w\left(a_{F}-|S|\right)^{2} / \sigma_{u}^{2}}, & S>z^{*} \\ S-\left[\sigma_{u}^{2}+\frac{1}{3}\left(a_{F}-|S|\right)^{2}\right] \widehat{\theta}, & z<S \leq z^{*} \\ 2 z, & S \leq z\end{cases}
$$

Moreover, the equilibrium price $P$ is a monotonic function of $S$, strictly increasing for $S>z$ but constant for $S \leq z$.

Obviously, our conjecture about the form of the price function is confirmed. Moreover, investors' stock holdings in equilibrium are given by:

$$
\begin{aligned}
& \theta_{I}= \begin{cases}\bar{\theta}+(1-w) \frac{S+\frac{1}{3}\left(a_{F}-|S|\right)^{2} \bar{\theta}}{\sigma_{u}^{2}+\frac{1}{3} w\left(a_{F}-|S|\right)^{2}}, & S>z^{*} \\
0, & S \leq z^{*}\end{cases} \\
& \theta_{U}= \begin{cases}\bar{\theta}-w \frac{S+\frac{1}{3}\left(a_{F}-|S|\right)^{2} \bar{\theta}}{\sigma_{u}^{2}+\frac{1}{3} w\left(a_{F}-|S|\right)^{2}}, & S>z^{*} \\
\widehat{\theta}, & S \leq z^{*}\end{cases}
\end{aligned}
$$

It is easy to show that $\theta_{I}$ is weakly increasing in $S$, and the short-sale constraint is binding only if $S \leq z^{*}$. Note that $S$ has a lower bound of $-a_{F}$. Thus, short-sale constraint is binding, at 


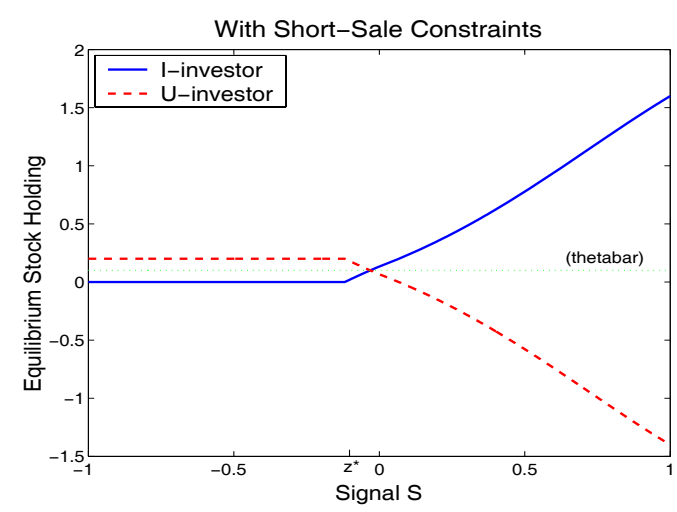

Figure 2: Investors' equilibrium stock holdings with short-sale constraints. The figure plots the equilibrium stock holdings of I-investors (the solid line) and U-investors, respectively, as a function of signal $S=\frac{1}{2}\left(F-\sigma_{u N} X_{I}\right)$. The parameter values are $a_{u}=a_{F}=a_{I}=1$, $\bar{\theta}=0.1$, and $w=0.5$.

least in some states of the economy, under condition (11). Figure 2 illustrates the equilibrium stock holdings of I- and U-investors, as a function of $S$.

The equilibrium described in Proposition 3 exhibits two interesting features. First, when $S$ becomes smaller than $z^{*}$ (but larger than $z$ ), I-investors' stock holding becomes zero in equilibrium. However, this does not imply that the equilibrium price fails to be informative about their information. In fact, in these states (i.e., $z<S \leq z^{*}$ ), the equilibrium price fully reveals $S$. Such a situation is perfectly consistent with a Walrasian equilibrium. In such an equilibrium, I-investors submit their demand function, which depends on their information, in particular $S$. For $z<S \leq z^{*}$, the market clearing price is such that it reveals $S$ and conditional on this information U-investors hold all the shares in equilibrium while I-investors end up holding none. Second, the equilibrium stock price becomes independent of $S$ when $S \leq z$. In these states, I-investors will simply withdraw from the market (i.e., submitting a zero demand for feasible prices). Consequently, the equilibrium price becomes completely uninformative. As we will see in the next section, the equilibrium exhibits different properties in these states (i.e., when $S \leq z$ ). In Section 5, we will discuss the robustness and additional economic justification of the Walrasian equilibrium obtained here in a more general setting.

\section{The Impact of Short-Sale Constraints on Asset Prices}

Given the market equilibrium in the presence of short-sale constraints, we now examine how they affect the informational efficiency of the market and the behavior of asset prices. We do so by simply comparing the equilibrium with short-sale constraints to the equilibrium without. 


\subsection{Short-Sale Constraints and Informational Efficiency}

Given that investors trade for both risk sharing and private information, the equilibrium price in general does not fully reveal investors' private information. In other words, the market is not informationally efficient. This is the case even without short-sale constraints, as shown in Section 3.2. U-investors remains uncertain about $F$ in equilibrium, although at a lower level than ex ante. However, as short-sale constraints are introduced, the market price becomes even less informative about $F$ as I-investors trade less in the market.
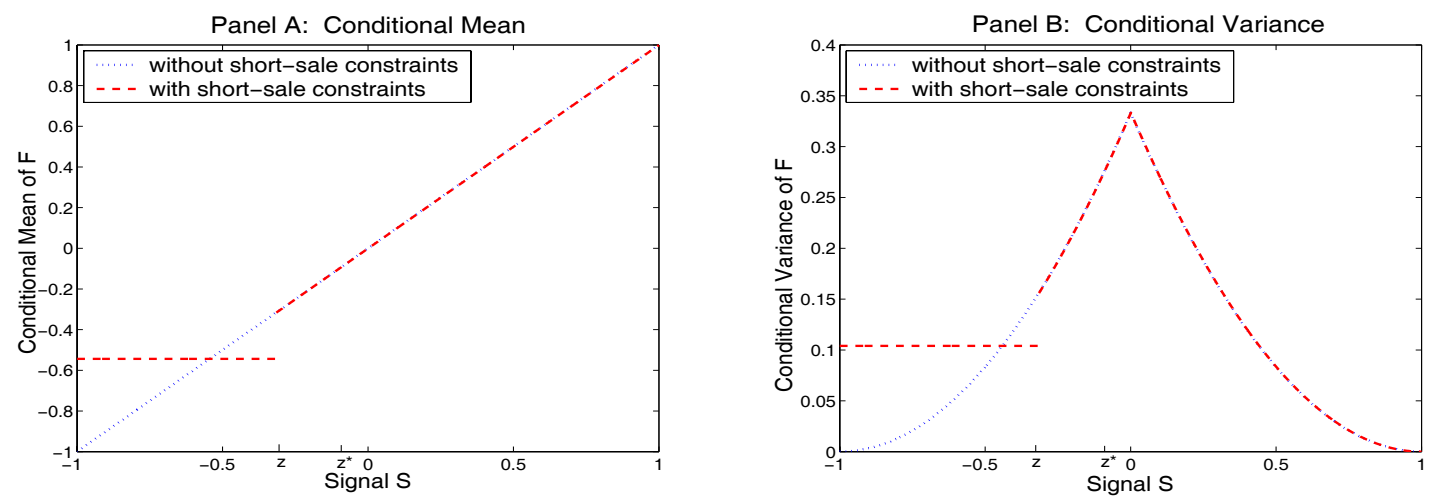

Figure 3: Moments of payoff conditional on price. The horizontal axis is I-investors' mixed signal $S=\frac{1}{2}\left(F-\sigma_{u N} X_{I}\right)$. The vertical axis is the mean and variance of $F$ conditional on equilibrium stock prices under different circumstances. The parameter values are $a_{u}=a_{F}=$ $a_{I}=1, \bar{\theta}=0.1$, and $w=0.5$.

In order to see the impact of short-sale constraints on the informational efficiency of the market, we plot in Figure 3 the conditional moments of $F$ as perceived by U-investors in equilibrium. (Their analytic expressions are given in Section 3.3.) The left panel shows the mean of $F$ conditional on the market price and the right panel shows the variance. In both panels, the dotted lines correspond to the case without short-sale constraints and the dashed lines correspond to the case with short-sale constraints.

For $S>z$, the market price reveals $S$ in both cases, with and without short-sale constraints, and the conditional moments of $F$ as perceived by U-investors are the same in the two cases. However, for $S \leq z$, the market price becomes uninformative in the case with short-sale constraints (see Proposition 3). For convenience, we refer to those states with $S \leq z$ as "uninformative states" in the presence of short-sale constraints. Obviously, when the economy falls into these states U-investors completely lose the ability to distinguish between them. Thus, the conditional mean and variance of $F$ are flat for these states (i.e., $S \leq z$ ), as Figure 3 shows. As a result, there is a discrete drop in both the conditional mean and variance of $F$ 
at $S=z$. As the price becomes uninformative, U-investors can only infer that $S \leq z$ (while for $S>z$ they can infer the precise value of $S$ ). The larger range of possible low values of $S$ (lower than $z$ ) leads U-investors to assign higher probabilities to low values of $F$, which gives a lower conditional mean. Intuitively, we expect the conditional variance to be higher as the price cease to reveal $S$ when there are short-sale constraints. As we will see below, this intuition indeed holds for these uninformative states. But conditional variance need not be higher for each uninformative state with short-sale constraints; it is higher for some states (those with $S$ far from $z$ ) but lower for other states (those with $S$ closer to $z$ ).

Given that short-sale constraints severely limit the amount of information the market price reveals in the uninformative states, we focus on the informational efficiency of the market in these states. We denote the set of these states by $\Omega_{B}=\{\omega: S \leq z\}$, where $\omega$ denotes an arbitrary state of the economy. First, we observe that for these states, the conditional mean and variance are constant, independent of the underlying state. In particular, we have $\mathrm{E}\left[F \mid P, \Omega_{B}\right]=\frac{1}{3}\left(2 z-a_{F}\right)$ and $\operatorname{Var}\left[F \mid P, \Omega_{B}\right]=\frac{2}{9}\left(z+a_{F}\right)^{2}$. Second, we consider the average effect of short-sale constraints on U-investors' information by comparing their conditional moments of $F$ for the uninformative states. (For other states, with or without short-sale constraints, U-investors extract the same amount of information from the market price.) We have the following result:

PROPOSITION 4 Let $\Omega_{B}=\{\omega: S \leq z\}$. Then,

$$
\begin{aligned}
\mathrm{E}\left[\mathrm{E}\left[F \mid P^{*}\right] \mid \Omega_{B}\right] & =\frac{1}{3}\left(2 z-a_{F}\right)=\mathrm{E}\left[\mathrm{E}[F \mid P] \mid \Omega_{B}\right] \\
\mathrm{E}\left[\operatorname{Var}\left[F \mid P^{*}\right] \mid \Omega_{B}\right] & =\frac{1}{6}\left(z+a_{F}\right)^{2}<\frac{2}{9}\left(z+a_{F}\right)^{2}=\mathrm{E}\left[\operatorname{Var}[F \mid P] \mid \Omega_{B}\right] .
\end{aligned}
$$

From (26a), we immediately conclude that under rational expectations short-sale constraints do not bias U-investors' expectations of future payoff. This is the insight of Diamond and Verrecchia (1987). However, (26b) clearly shows that short-sale constraints do increase Uinvestors' perceived uncertainty about future payoff.

Since for other states, i.e. $\omega \notin \Omega_{B}$, the conditional mean and variance are the same with and without short-sale constraints, the following result is obvious:

COROLLARY 2 Short-sale constraint does not bias U-investors' expectation of future payoff, but it does increase their perceived uncertainty, as measured by their conditional variance, about future payoff. 
As we see below, it is this adverse effect on perceived uncertainty that will lead to an adverse impact on price by short-sale constraints when investors are risk averse. If we use U-investors' perceived variance of $F$ conditional on market price as a measure of the market's informational inefficiency, then we have:

COROLLARY 3 Short-sale constraint reduces market's informational efficiency.

\subsection{Short-Sale Constraints and Market Crashes}

We now consider the impact of short-sale constraints on the equilibrium price. Figure 4 plots the price as a function of $S$. The dotted line corresponds to the case without short-sale constraints and the dashed line corresponds to the case with short-sale constraints.

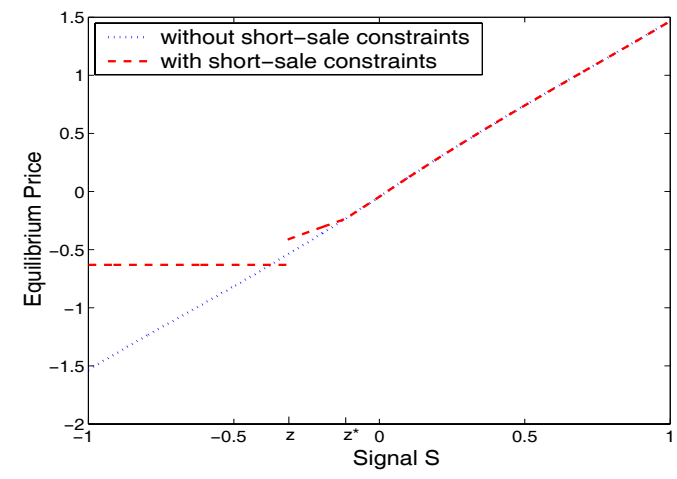

Figure 4: Equilibrium stock price. The dashed line plots the equilibrium price as a function of signal $S=\frac{1}{2}\left(F-\sigma_{u N} X_{I}\right)$ with short-sale constraints while the dotted line plots the equilibrium price without short-sale constraints. The parameter values are $a_{u}=a_{F}=a_{I}=1$, $\bar{\theta}=0.1$, and $w=0.5$.

First, we note that for $S>z^{*}$, where $z^{*}$ is given in Proposition 3, the equilibrium price is the same for the two cases. This is intuitive as in states with $S>z^{*}$ the short-sale constraints are not binding for I-investors. Next, for $z<S \leq z^{*}$, the price with short-sale constraints, $P$ (the dashed line), is higher than the price without short-sale constraints, $P^{*}$ (the dotted line). Here, we have the situation in which short-sale constraints are binding for I-investors. Since their selling, either due to the need to hedge non-traded risk or negative information on future payoff, is curbed by the constraints, less downward pressure is exerted on the price. Thus, we see a higher price. This corresponds to the situation commonly discussed in the literature. ${ }^{7}$ However, at $S=z$, we observe a discrete drop in the stock price. This corresponds to

\footnotetext{
${ }^{7}$ See, for example, Harrison and Kreps (1978) and Miller (1977).
} 
the situation when price suddenly becomes uninformative and U-investors perceive a sharp increase in uncertainty about the stock's future payoff. Since now U-investors are the only marginal investors in the market and they are risk averse, the increase in their perceived uncertainty will force the price to drop in order to attract them to hold the stock. Such a discrete price drop corresponds to a market crash. It is important to note that for both $S>z$ (normal states) and $S \leq z$ (states of crash), investors' expectations of the stock payoff are unbiased.

Previous work have also attributed to short-sale constraints as a possible cause for market crashes. For example, Harrison and Kreps (1978) and Scheinkman and Xiong (2003) consider models in which investors have heterogeneous beliefs but face short-sale constraints. By holding out less optimistic investors, short-sale constraints allow more optimistic investors to drive up prices in certain states. In particular, the equilibrium price can rise significantly above what is justifiable based on investors' expectations of future payoffs, leading to price bubbles. To the extent that bubbles may burst at some point, these papers also provide a possible story for market crash. But these papers do not explicitly generate crashes. Using a similar model, Hong and Stein (2003) further show that short-sale constraints lead to negatively skewed return distributions, which is consistent with several characteristics of market crashes.

Our model and its predictions differ from these models in several important aspects. First, we assume no irrationality. Investors fully condition on the information conveyed by market prices in making their trading decisions. Second, in our model, market crashes are associated with discrete price drops in the absence of major shocks. This form of market crash is more drastic than the form of negative skewness considered by Hong and Stein (2003). Third and more importantly, in our model a market crash is generated by a sudden surge in uncertainty as perceived by less informed investors rather than a change in asset value as perceived by investors. It is the latter that previous work has focused on. In fact, most of the existing models on the impact of short-sale constraints assume risk-neutrality for marginal investors. Fourth, in our model price drop is accompanied with an increase in risk as perceived by investors. As a result, return and volatility are negatively correlated, especially during a crash. This is consistent with the empirical evidence. ${ }^{8}$ This is also consistent with the fact that stock price crashes appear to involve more confusion and uncertainty rather than transparency and clarity, while explanations based on the revelation-of-news or burst of bubbles imply the opposite.

\footnotetext{
${ }^{8}$ See, for example, Black (1976), Christie (1982) and French, Schwert, and Stambaugh (1987).
} 


\subsection{The Average Price Level Under Short-Sale Constraints}

We next compare the average values of $P$ and $P^{*}$ to examine the overall impact of short-sale constraints on the equilibrium price. As our discussion in Section 3.1 shows, in the absence of information asymmetry, short-sale constraints only curb large sales for risk-sharing, and thus increase prices. In the presence of information asymmetry, however, curbing trades motivated by private information makes the price less informative to U-investors, who are the marginal investors in the market. Given that investors are risk averse, the reduction in the informativeness of the market has the effect of decreasing the stock price. The net effect of short-sale constraints on the price depends on the relative importance of information asymmetry. From equations (17) and (24), we have the following proposition:

PROPOSITION 5 For every parameter set $\left\{a_{u}, a_{F}, \bar{\theta}\right\}$, there exists $0<\underline{w}<1$ such that for all $w<\underline{w}, \mathrm{E}[P]-\mathrm{E}\left[P^{*}\right] \leq 0$.

Thus one of our central results is that short-sale constraints can cause the average price level to fall when information asymmetry is important. This is in sharp contrast to the previous work (e.g., Miller (1977) and Diamond and Verrecchia (1987)). Figure 5 illustrates how the impact of short-sale constraints on the stock price level varies with $w$, the fraction of I-investors.
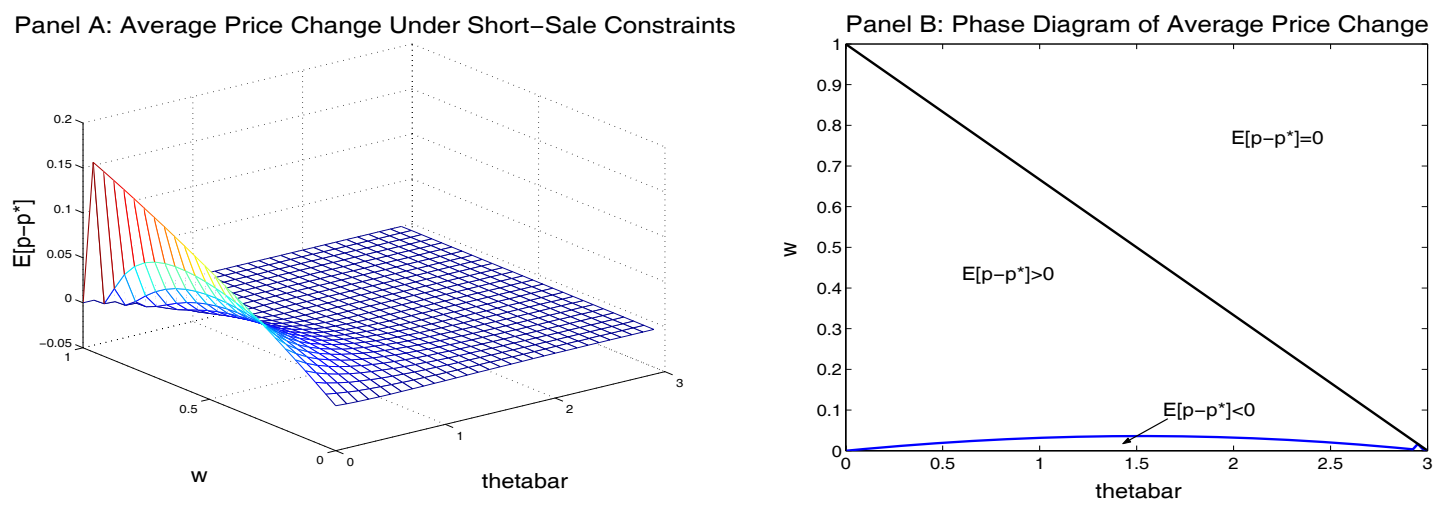

Figure 5: The impact of short-sale constraints on asset prices. The left panel plots $\mathrm{E}\left[P-P^{*}\right]$, the average price change due to short-sale constraints, for different values of $w$ and $\bar{\theta}$. The right panel plots the phase diagram, the ranges of parameters for a positive, zero and negative $\mathrm{E}\left[P-P^{*}\right]$, respectively. The remaining parameters are set as the following values: $a_{u}=a_{F}=a_{I}=1$.

In order to see intuitively why small $w$ leads to a negative impact on stock prices, consider the extreme situation where $w$ is close to zero, i.e., the fraction of I-investor's population is very small. In this case, even though short-sale constraints increase their optimal demands, the corresponding increase of aggregate market demand is near zero. Consequently, the allocational 
effect of short-sale constraints on asset prices is negligible. However, the informational effect of short-sale constraints can be nontrivial. Despite the small population weight, I-investors provide an important source of information to the market through their trades. In particular, the amount of information revealed by the market price can remain substantial even when the total size of trades from I-investors is very small. And its impact on the equilibrium price can be significant. ${ }^{9}$ Therefore, for small $w$, the informational effect of short-sale constraints becomes dominant, which leads to a decrease in prices.

To illustrate the informational effect of short-sale constraints more clearly, let us focus on the extreme situation in which $w=0^{+}$. In this case, the allocational effect of shortsale constraints on asset prices is actual zero, so the price change is purely attributed to the informational effect. By calculations the difference in expected prices is given as:

$$
\mathrm{E}[P]-\mathrm{E}\left[P^{*}\right]=-\frac{\bar{\theta}\left(z+a_{F}\right)^{4}}{36 a_{F}^{2}} .
$$

Equation (27) demonstrates the informational effect of short-sale constraints on asset prices. This effect depends on other aspects of the economy. In particular, it depends on the degree of information asymmetry between the two classes of investors, which can be measured by $\sigma_{F}$, and the risk of the stock, as measured by $\sigma_{u}$. The following proposition describes the dependence.

PROPOSITION 6 For $w=0^{+}$, we have

$$
\frac{\partial \mathrm{E}\left[P-P^{*}\right]}{\partial \sigma_{F}}<0, \quad \frac{\partial \mathrm{E}\left[P-P^{*}\right]}{\partial \sigma_{u}}>0 .
$$

Note that $\mathrm{E}\left[P-P^{*}\right] \leq 0$ always holds for $w=0^{+}$, the results above are intuitive. As $\sigma_{F}$, the measure of information asymmetry, increases, the informational effect of short-sale constraints drives asset price to decline more. There are two reasons. First, with a larger $\sigma_{F}$, I-investors will trade more aggressively based on their private information. Consequently, they are more likely to run into the short-sale constraint, i.e., the likelihood of stock prices being uninformative increases. Second, the larger degree of initial information asymmetry, the larger increase of U-investors' perceived uncertainty when short-sale constraints are binding. So the stock price will decline more under short-sale constraints. The impact of the risk in the stock's payoff, given by $\sigma_{u}$, on $\mathrm{E}\left[P-P^{*}\right]$ is just the opposite. As $\sigma_{u}$ increases, I-investors become less aggressive in trading both for risk-sharing and speculating on their private information, as a

\footnotetext{
${ }^{9}$ In a rational expectations setting, an informed investor's impact on the market is not limited by the size of his trades. See Wang (1993) for a more detailed discussion of this point.
} 
result, the likelihood for them to be short-sale constrained, or the prices to be uninformative becomes smaller. Thus, the informational impact of short-sale constraint on asset prices is weaker, as Proposition 6 states.

From Propositions 5 and 6 , we see that the informational effect of short-sale constraint becomes dominant when information asymmetry is important. So the following result is obvious:

COROLLARY 4 In a market with high degree of information asymmetry, short-sale constraints can increase the cost of capital.

There is an extensive empirical literature on the impact of short-sale constraints on stock prices. Most of the empirical studies focus on the individual stocks in the US stock market. Using different proxies for the constrains, the majority find that short-sale constraints are associated with stock overpricing, but a few do not. ${ }^{10}$ However, some international marketwide studies yield different results. ${ }^{11}$ For example, Charoenrook and Daouk (2005) examine the short-selling regulation and practice of 111 countries. Using both event-study and panel regression methods, they find that the cost of equity is significantly lower when short-selling becomes possible. ${ }^{12}$

Our model provides a possible explanation. Perhaps in highly developed financial market such as US, the degree of information asymmetry is relatively lower, so the allocational effect of short-sale constraints dominates and market price goes up, as shown in Section 3.1. However, in other emerging markets which have higher information asymmetry, short sales constraint may have greater informational effect that outweigh its allocational effect, as Proposition 5 and Corollary 4 suggest. ${ }^{13}$

\footnotetext{
${ }^{10}$ For example, Asquith, Pathak and Ritter (2005) and Boehme, Danielsen and Sorescu (2005) use short interest to measure the level of short-sale constrains, Figlewski and Webb (1993), Danielson and Sorescu (2001), and Mayhew and Mihov (2005) employ option introduction as a proxy of relaxation of short-sale constraints, Chen, Hong and Stein (2002) and Nagel (2005) use institutional ownership, Jones and Lamont (2002) uses lending fees of stocks, and D'Avolio (2002) uses loan supply and loan fees as proxy for short-sale constraints.

${ }^{11}$ See, for example, Bris, Goetzmann and Zhu (2004), Charoenrook and Daouk (2005), and Gulen and Mayhew (2000).

${ }^{12}$ Examining 31 short-selling rule changes, Charoenrook and Daouk (2005) find a significantly positive abnormal return of $3.6 \%$ when rules are relaxed. Moreover, using panel regressions, they find the cost of equity is lower by $1.07 \%$ per year when short-selling is possible.

${ }^{13}$ International evidence at the individual stock level is relatively scarce. Chang, Cheng and Yu (2006) examine the short-sales practice in the Hong Kong market, where individual stocks can only be sold short when they meet certain size and liquidity criteria and are added to an eligible list. Their evidence suggests that stock price decreases when short-sale constraints are relaxed, especially under the presence of heterogeneity in investors' beliefs. As the stocks added to the list are the largest and most liquid ones in the market, it
} 


\subsection{Price Volatility}

Let us now consider how short-sale constraints affect the volatility of prices in the current model. As we mentioned before, short-sale constraints limit both allocational and informational trades of investors. However, curbing these two types of trades have different effects on the behavior of equilibrium price, including its volatility. In order to illustrate these two difference effects, we first examine the case of symmetric information, which is defined in Section 3.1. From equations (9) and (10), we have

$$
\begin{aligned}
& \operatorname{Var}\left[P^{*}\right]=\left(1+w^{2}\right) a_{F}^{2} \\
& \operatorname{Var}[P]=a_{F}^{2}+w^{2}\left[\frac{a_{F}^{2}}{6}+\frac{\left(\sigma_{u}^{2} \widehat{\theta}\right)^{2}}{2}-\frac{\left(\sigma_{u}^{2} \widehat{\theta}\right)^{3}}{3 a_{F}}-\frac{\left(a_{F}-\sigma_{u}^{2} \widehat{\theta}\right)^{2}}{4 a_{F}^{2}}\right]
\end{aligned}
$$

Comparing the price volatility with and without short-sale constraints, we have the following result:

PROPOSITION 7 Under symmetric information, short-sale constraints always lead to a decrease in the stock price volatility, i.e., $\operatorname{Var}[P] \leq \operatorname{Var}\left[P^{*}\right]$.

The intuition behind this result is as follows: Forbidding short selling limits the demand fluctuation due to (negative) endowment shocks, which will in turn, reduces price volatility.

The situation become more complex when investors have heterogenous information. In this case, short-sale constraints affect not only investors' stocks holdings but also their information set. On one hand, like the case of symmetric information, constraining short selling smooths the random demand shocks, which could reduce price volatility. On the other hand, shortsale constraints also decrease the informativeness of market price and increase the perceived uncertainty of U-investors. This increased in perceived risk will drive price variance upward.

Using the results of Propositions 2 and 3, we can calculate the price variance with and without short-sale constraints, respectively. The comparative results are shown in Figure 6. From Figure 6 we can see that in the presence of asymmetric information, it is not the case that short-sale constraints always stabilize prices and reduce price volatility. In particular, when $w$, the fraction of I-investor is small, the informational effect of short-sale constraints becomes the dominating factor, which leads to an increase of asset price volatility, instead of a decrease.

could be interpreted as consistent with our model in that the effect might well be due to the dominance of allocational need rather than the information asymmetry effect. 

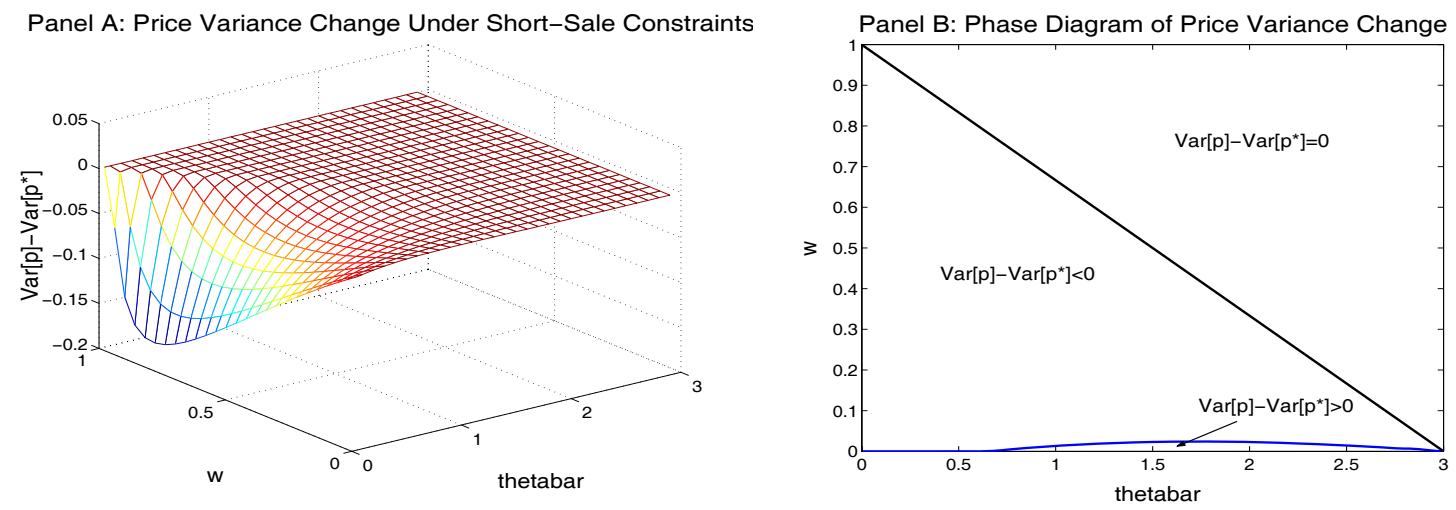

Figure 6: The effects of short-sale constraints on asset price volatility. The left panel plots $\operatorname{Var}[P]-\operatorname{Var}\left[P^{*}\right]$, the price variance change due to short-sale constraints, for different values of $w$ and $\bar{\theta}$. The right panel shows the "phase diagram", the parameter ranges for which $\operatorname{Var}[P]-\operatorname{Var}\left[P^{*}\right]$ is negative, zero and positive, respectively. The other parameters are set as the following values: $a_{u}=a_{F}=a_{I}=1$.

Our model ties in nicely with several empirical findings. For example, Gulen and Mayhew (2000) study the introduction of equity-index futures trading (which can be viewed as relaxation of short-sale constraints) and market volatility changes. They find that in most markets, introduction of stock index futures appears to have contributed to a decrease in price variance. In the U.S. and Japan, however, the opposite appears to be the case. These results support our prediction that in markets with higher information asymmetry, allowing short sales can actually increase their informational efficiency and stability.

\subsection{Price Skewness}

Several authors have attributed return skewness to short-sale constraints. For example, Hong and Stein (2003) have argued that short-sale constraints can lead to negative skewness in stock returns, which they associate with market crashes (see also Yuan (2004)). For comparison, we also examine how short-sale constraints affects return skewness in our model.

Given our setting, we have two short-horizon stock returns:

$$
R_{0}=P-P_{-1}, \quad R_{1}=V-P=F-P+u
$$

where $P_{-1}$ denotes the equilibrium stock price before date 0 , which is a constant. The calculation of $P_{-1}$ is straightforward, but is omitted here for brevity. For the skewness of two short-horizon returns, we have $\operatorname{Skew}\left[R_{0}\right]=\operatorname{Skew}[P]$ and $\operatorname{Skew}\left[R_{1}\right]=\operatorname{Skew}[F-P] \cdot{ }^{14}$ We also

\footnotetext{
${ }^{14}$ The skewness of a random variable is defined as Skew $[X]=\mathrm{E}\left[(X-\mathrm{E}[X])^{3}\right]$.
} 
define the average skewness of short-horizon returns by

$$
\overline{\text { Skew }}[R]=\left(\operatorname{Skew}\left[R_{0}\right]+\operatorname{Skew}\left[R_{1}\right]\right) / 2 \text {. }
$$

We first consider the case of symmetric information. From equations (9) and (10), we have

$$
\begin{aligned}
& \operatorname{Skew}\left[R_{0}^{*}\right]=\operatorname{Skew}\left[R_{1}^{*}\right]=0 \\
& \operatorname{Skew}\left[R_{0}\right]=-\operatorname{Skew}\left[R_{1}\right]=\frac{w^{3}\left(a_{F}+\sigma_{u}^{2} \widehat{\theta}\right)^{4}}{2048 a_{F}^{5}}\left[\left(3 a_{F}-\sigma_{u}^{2} \widehat{\theta}\right)^{4}-\left(a_{F}+\sigma_{u}^{2} \widehat{\theta}\right)^{4}\right]
\end{aligned}
$$

where $R_{0}^{*}$ and $R_{1}^{*}$ denote returns in the absence of short-sale constraints. Comparing the price skewness with and without short-sale constraints, the following result is immediate:

PROPOSITION 8 Under symmetric information, Skew $\left[R_{0}\right] \geq \operatorname{Skew}\left[R_{0}^{*}\right]=0$, Skew $\left[R_{1}\right] \leq$ Skew $\left[R_{1}^{*}\right]=0$, and $\overline{\text { Skew }}[R]=\overline{\text { Skew }}\left[R^{*}\right]=0$.

The intuition behind this result is straightforward: As mentioned in Section 3.1, short-sale constraints prevent investors' stock demand at date 0 from dropping below zero. This lower bound on stock demand provides a lower bound on the stock price, which gives rise to positive skewness in the distribution of $P$ or $R_{0}$. At date 1 , the true payoff $V$ is realized, which is symmetrically distributed. The positive skewness in $P$ then leads to a negative skewness in return $R_{1}=V-P$. The above result suggests that under symmetric information the impact of short-sale constraints on the skewness of short-horizon returns is mixed. Moreover, the average skewness of short-horizon returns, $\overline{\text { Skew }}[R]$, remains at zero under symmetric information, independent of short-sale constraints.

Now we turn to the case with information asymmetry. In this case, analytical expression for return skewness is not available and we rely on numerical analysis. Let us first examine return skewness without short-sale constraints. We find that in general Skew $\left[R_{0}^{*}\right]$ becomes positive under asymmetric information, which is different from the case under symmetric information. Although in our model underlying shocks $\left(F\right.$ and $\left.X_{I}\right)$ have symmetric distributions, the equilibrium price, given in (17), does not. This is mainly because the conditional variance of underlying shocks as perceived by the uninformed investors is a non-linear function of their signal $S$, partially due to the uniform distribution we assumed. The skewness for $R_{1}^{*}$, however, can be positive or negative as Figure 7 shows. Panel A of Figure 7 plots Skew $\left[R_{1}^{*}\right]$ for different values of $w$ and $\bar{\theta}$. Panel $\mathrm{B}$ shows the range of parameters for which Skew $\left[R_{1}^{*}\right]$ is positive or negative. The average skewness, $\overline{\text { Skew }}\left[R^{*}\right]$, is in general positive. This 

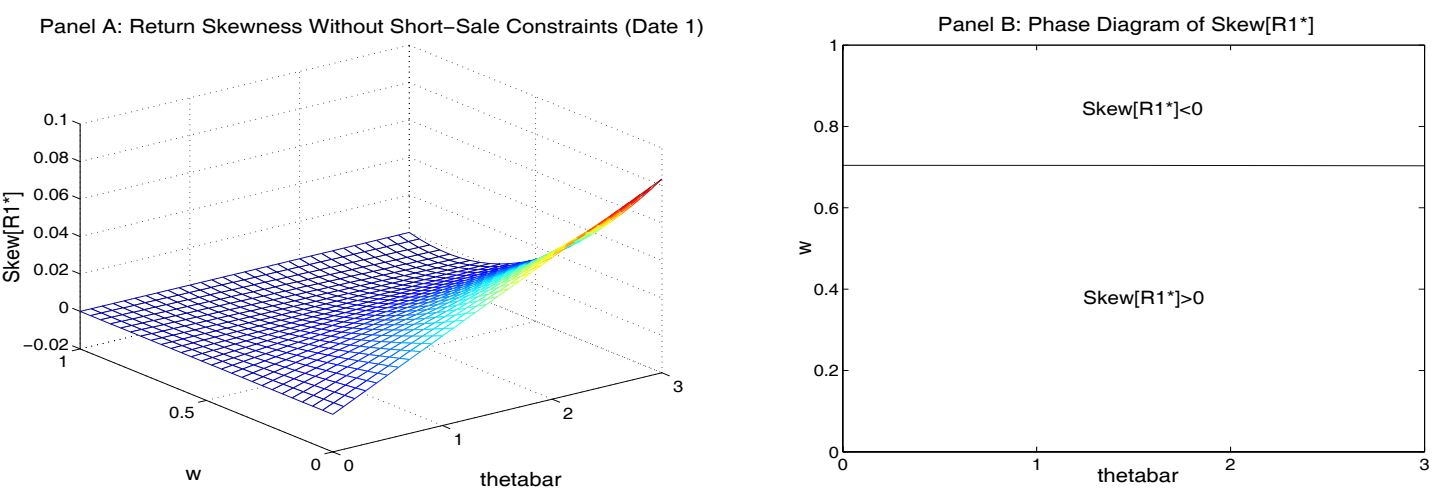

Figure 7: Return skewness without short-sale constraints. Panel A plots the stock return skewness Skew $\left[R_{1}^{*}\right]$ without short-sale constrains for different values of $w$ and $\bar{\theta}$. Panel B shows the "phase diagram" of Skew $\left[R_{1}^{*}\right]$, the parameter ranges for which it is negative, zero and positive, respectively. The other parameters are set as the following values: $a_{u}=a_{F}=a_{I}=1$.

(1) Return skewness for return $R_{0}$
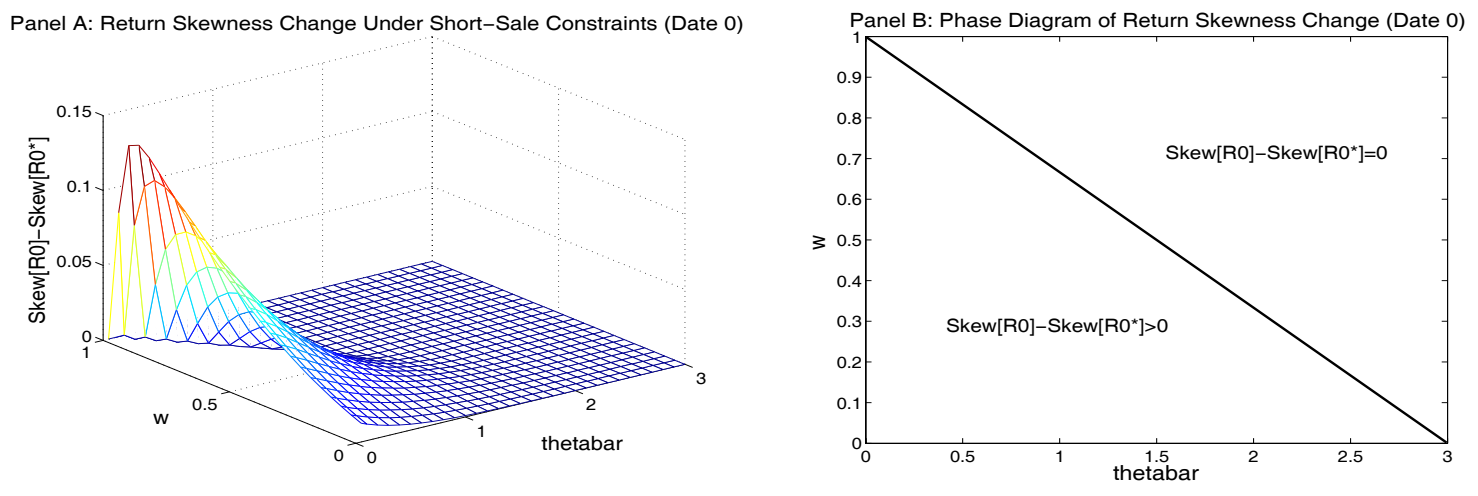

(2) Return skewness for return $R_{1}$
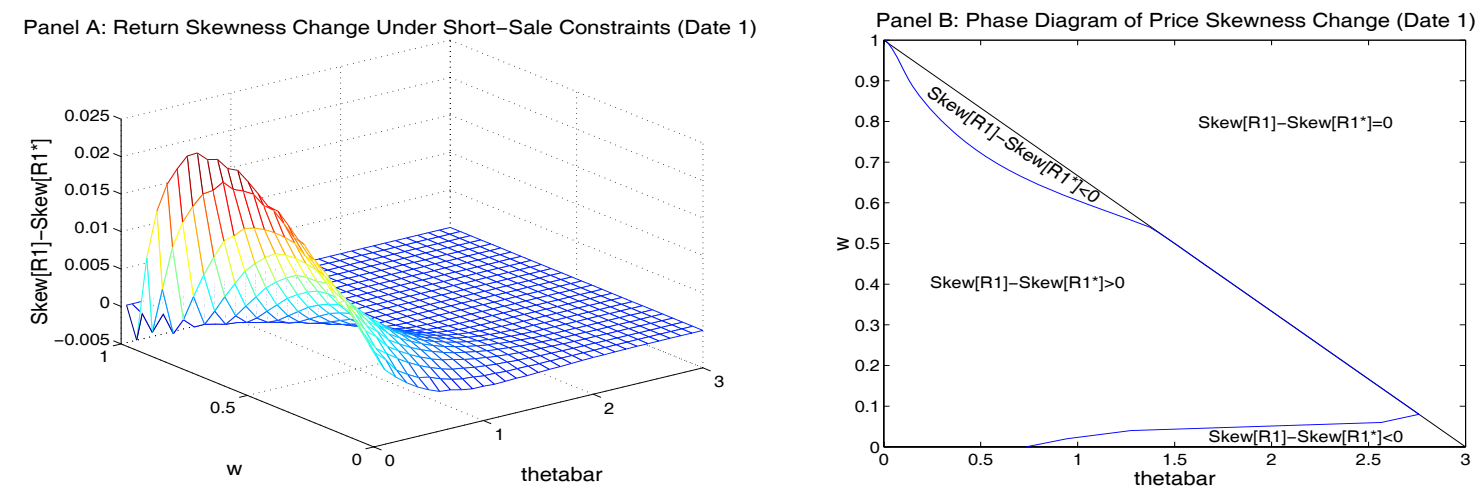

Figure 8: The impact of short-sale constraints on return skewness. The left two panels plot Skew $\left[R_{0}\right]-\operatorname{Skew}\left[R_{0}^{*}\right]$ and Skew $\left[R_{1}\right]-\operatorname{Skew}\left[R_{1}^{*}\right]$, changes in skewness of return $R_{0}$ and $R_{1}$, respectively, due to short-sale constraints, for different values of $w$ and $\bar{\theta}$. The right panels show the "phase diagram," the parameter ranges for which $\operatorname{Skew}\left[R_{0}\right]-\operatorname{Skew}\left[R_{0}^{*}\right]$ and Skew $\left[R_{1}\right]-$ Skew $\left[R_{1}^{*}\right]$ are negative, zero and positive, respectively. The other parameters are set as the following values: $a_{u}=a_{F}=a_{I}=1$. 
suggests that Skew $\left[R_{1}^{*}\right]$, when it is negative, is small in magnitude. For brevity, we omit the corresponding figures for Skew $\left[R_{0}^{*}\right]$ and $\overline{\operatorname{Skew}}\left[R^{*}\right]$.

Next, we consider how short-sale constraints affect return skewness by comparing the cases with and without them. Figure 8(1) demonstrates the change in skewness for return $R_{0}$, Skew $\left[R_{0}\right]$ - Skew $\left[R_{0}^{*}\right]$. Clearly, under asymmetric information, short-sale constraints usually increase the skewness of return $R_{0}$. This result is the same as that under symmetric information. The situation is slightly different for $R_{1}$. In particular, Skew $\left[R_{1}\right]-\operatorname{Skew}\left[R_{1}^{*}\right]$ can be positive or negative. As Figure 8(2) shows, for small values of $w$, the relative influence of information asymmetry is important and short-sale constraints can cause Skew $\left[R_{1}\right]$ to decrease.

Figure 9 shows how short-sale constraints impact average return skewness, i.e., $\overline{\text { Skew }}[R]-$ $\overline{\text { Skew }}\left[R^{*}\right]$. From the phase diagram in Panel B, it is obvious that when the relative influence of asymmetric information is important (i.e., small $w$ ), short-sale constraints can decrease the average skewness.
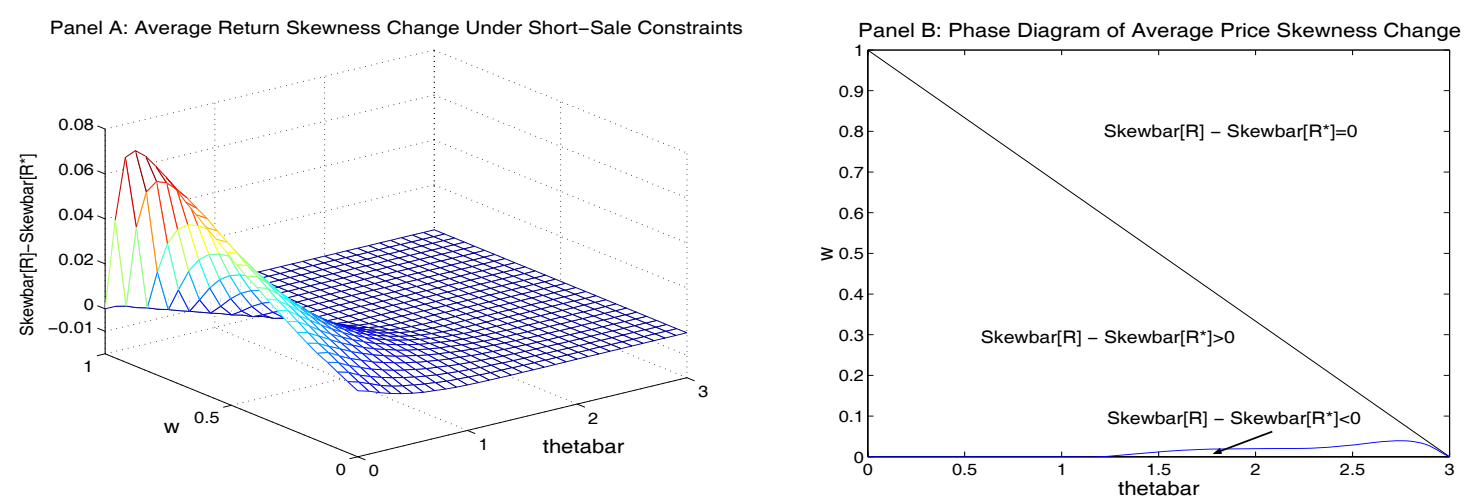

Figure 9: The impact of short-sale constraints on average return skewness. The left panel plots $\overline{\text { Skew }}[R]-\overline{\text { Skew }}\left[R^{*}\right]$, the average return skewness change due to short-sale constraints, for different values of $w$ and $\bar{\theta}$. The right panel shows the "phase diagram," the parameter ranges for which $\overline{\text { Skew }}[R]-\overline{\text { Skew }}\left[R^{*}\right]$ is negative, zero and positive, respectively. The other parameters are set as the following values: $a_{u}=a_{F}=a_{I}=1$.

Our results on how short-sale constraints affect short-horizon return skewness are qualitatively similar to those obtained by Hong and Stein (2003). The existing empirical work is consistent with our results. For example, Bris, Goetzman and Zhu (2004) find that in markets where short selling is either prohibited or not practiced, market returns display significantly less negative skewness, which can be related to Skew $\left[R_{0}\right]$ or Skew $[R]$. However, by examining the relation between short-sale constraints and earnings announcements, Reed (2003) finds that under short-sale constraints, the distribution of announcement-day returns is more 
left-skewed, which can be related to Skew $\left[R_{1}\right]$.

\section{The General Case}

In the above discussion, we only considered the simple case when only the I-investors have trading needs and face short-sale constraints (i.e., $\sigma_{U}=0$ and $b_{I}=\infty$ ). We also imposed parameter restriction (5) to simplify solution. Although this case is sufficient to demonstrate the impact of short-sale constraints on asset prices, for completeness, we present in this section the solution to the general case when both classes of investors have trading needs and face short-sale constraints. We still maintain the parameter restriction (5) for brevity in exposition. The solution to the most general case is omitted here but available upon request.

We start by conjecturing the form of the price function:

CONJECTURE 3 In the presence of short-sale constraints, the stock price, denoted by $P$, only depends on $S=\frac{1}{2}\left(F-\sigma_{u N} X_{I}\right)$ and $X_{U}$. Moreover, conditional on $X_{U}$, it is a strictly increasing function of $S$ for $S>z\left(X_{U}\right)$ and a constant for $S \leq z\left(X_{U}\right)$, where $-a_{F} \leq z\left(X_{U}\right) \leq 0$ is a function of $X_{U}$.

Under the conjectured price function, we derive the investors' optimal demand for the stock. For I-investors, from Equation (8) we have:

$$
\theta_{I}=\max \left[(2 S-P) / \sigma_{u}^{2},-b_{I}\right]
$$

For U-investors, Lemma 4 still holds and we have:

LEMMA 6 Under the price function in Conjecture 3, the U-investors' demand for the stock is given by

$$
\theta_{U}= \begin{cases}\max \left[\frac{S-P-\sigma_{u N} X_{U}}{\sigma_{u}^{2}+\frac{1}{3}\left(a_{F}-|S|\right)^{2}},-b_{U}\right], & P>\widehat{p}\left(X_{U}\right) \\ \max \left[\frac{\frac{1}{3}\left[2 z\left(X_{U}\right)-a_{F}\right]-P-\sigma_{u N} X_{U}}{\sigma_{u}^{2}+\frac{2}{9}\left[z\left(X_{U}\right)+a_{F}\right]^{2}},-b_{U}\right], & P \leq \widehat{p}\left(X_{U}\right)\end{cases}
$$

where $\widehat{p}\left(X_{U}\right)$ is the stock price at $S=z\left(X_{U}\right)$.

Given the optimal stock demand of both classes of investors, we now solve for the equilibrium. For convenience, we define

$$
\widehat{\theta}_{I}=\left[\bar{\theta}+(1-w) b_{U}\right] / w, \quad \widehat{\theta}_{U}=\left(\bar{\theta}+w b_{I}\right) /(1-w) .
$$


Clearly, $\widehat{\theta}_{I}$ is the stock holding of each I-investor when all U-investors are short-sale constrained, i.e., short-selling the maximum amount $b_{U}$, and $\widehat{\theta}_{I}$ is the stock holding of each U-investor when all I-investors are short-sale constrained, i.e., short-selling the maximum amount $b_{I}$. We also define

$$
\begin{aligned}
& x_{1}=\left[-\left(\widehat{\theta}_{U}+b_{I}\right)+a_{F} / \sigma_{u}^{2}\right] / h, \quad x_{2}=\left[-\left(\widehat{\theta}_{U}+b_{I}\right)-\left(\sigma_{F}^{2} / \sigma_{u}^{2}\right) \widehat{\theta}_{U}\right] / h \\
& x_{3}=\left[\left(\widehat{\theta}_{I}+b_{U}\right)-a_{F} / \sigma_{u}^{2}\right] / h, \quad x_{4}=\left[\left(\widehat{\theta}_{I}+b_{U}\right)+\left(\sigma_{F}^{2} / \sigma_{u}^{2}\right) b_{U}\right] / h .
\end{aligned}
$$

The equilibrium is given in the following proposition:

\section{PROPOSITION 9 Let}

$$
\begin{aligned}
& z\left(X_{U}\right)= \begin{cases}-a_{F}-\left(3 / \widehat{\theta}_{U}\right)\left[1-\sqrt{1+\frac{1}{2} \sigma_{u N} \widehat{\theta}_{U}\left(x_{1}-X_{U}\right)}\right], & X_{U}<x_{1} \\
-a_{F}, & X_{U} \geq x_{1}\end{cases} \\
& z^{*}\left(X_{U}\right)= \begin{cases}a_{F}-\left(\frac{3}{2} / \widehat{\theta}_{U}\right)\left[1-\sqrt{1+\frac{4}{3} \sigma_{u N} \widehat{\theta}_{U}\left(x_{1}-X_{U}-2 \widehat{a}_{F}\right)}\right], & X_{U}<x_{2} \\
-a_{F}-\left(\frac{3}{2} / \widehat{\theta}_{U}\right)\left[1-\sqrt{1+\frac{4}{3} \sigma_{u N} \widehat{\theta}_{U}\left(x_{1}-X_{U}\right)}\right], & x_{2} \leq X_{U}<x_{1} \\
-a_{F}, & X_{U} \geq x_{1}\end{cases} \\
& \widehat{z}\left(X_{U}\right)= \begin{cases}a_{F}, & X_{U} \leq x_{3} \\
a_{F}+\left(\frac{3}{2} / b_{U}\right)\left[1-\sqrt{1+\frac{4}{3} \sigma_{u N} b_{U}\left(X_{U}-x_{3}\right)}\right], & x_{3}<X_{U} \leq x_{4} \\
-a_{F}+\left(\frac{3}{2} / b_{U}\right)\left[1-\sqrt{1+\frac{4}{3} \sigma_{u N} b_{U}\left(X_{U}-x_{3}-2 \widehat{a}_{F}\right)}\right], & X_{U}>x_{4}\end{cases}
\end{aligned}
$$

where $\widehat{a}_{F}=a_{F} / \sigma_{u N}$. Then, $\widehat{z}\left(X_{U}\right) \geq-\sigma_{u N} X_{U} \geq z^{*}\left(X_{U}\right) \geq z\left(X_{U}\right)$ and $z\left(X_{U}\right) \leq 0$. When all investors are constrained from short selling, the equilibrium stock price is given by

$$
P= \begin{cases}2 S-\sigma_{u}^{2} \widehat{\theta}_{I}, & S>\widehat{z}\left(X_{U}\right) \\ 2 S-\sigma_{u}^{2} \bar{\theta}-(1-w) \frac{S+\frac{1}{3}\left(a_{F}-|S|\right)^{2} \bar{\theta}+\sigma_{u N} X_{U}}{1+\frac{1}{3} w\left(a_{F}-|S|\right)^{2} / \sigma_{u}^{2}}, & z^{*}\left(X_{U}\right)<S \leq \widehat{z}\left(X_{U}\right) \\ S-\left[\sigma_{u}^{2}+\frac{1}{3}\left(a_{F}-|S|\right)^{2}\right] \widehat{\theta}_{U}-\sigma_{u N} X_{U}, & z\left(X_{U}\right)<S \leq z^{*}\left(X_{U}\right) \\ 2 z\left(X_{U}\right)+\sigma_{u}^{2} b_{I}, & S \leq z\left(X_{U}\right)\end{cases}
$$

Moreover, conditional on $X_{U}$, the equilibrium price $P$ is a monotonic function of $S$, strictly increasing for $S>z\left(X_{U}\right)$ but constant for $S \leq z\left(X_{U}\right)$. 
Clearly, our conjecture about the form of the price function is confirmed. Given the equilibrium price, the investors' equilibrium stock holdings are given by:

$$
\begin{aligned}
& \theta_{I}= \begin{cases}\widehat{\theta}_{I}, & S>\widehat{z}\left(X_{U}\right) \\
\bar{\theta}+(1-w) \frac{S+\frac{1}{3}\left(a_{F}-|S|\right)^{2} \bar{\theta}+\sigma_{u N} X_{U}}{\sigma_{u}^{2}+\frac{1}{3} w\left(a_{F}-|S|\right)^{2}}, & z^{*}\left(X_{U}\right)<S \leq \widehat{z}\left(X_{U}\right) \\
-b_{I}, & S \leq z^{*}\left(X_{U}\right)\end{cases} \\
& \theta_{U}= \begin{cases}-b_{U}, & S>\widehat{z}\left(X_{U}\right) \\
\bar{\theta}-w \frac{S+\frac{1}{3}\left(a_{F}-|S|\right)^{2} \bar{\theta}+\sigma_{u N} X_{U}}{\sigma_{u}^{2}+\frac{1}{3} w\left(a_{F}-|S|\right)^{2}}, & z^{*}\left(X_{U}\right)<S \leq \widehat{z}\left(X_{U}\right) \\
\widehat{\theta}_{U}, & S \leq z^{*}\left(X_{U}\right)\end{cases}
\end{aligned}
$$

We see that the result in Proposition 9 is qualitatively similar with that of Proposition 3. The major differences are two-fold: U-investors have risk-sharing motives of their own and also face short-sale constraints. As the U-investors trade only for risk-sharing, the direct impact of short-sale constraints on their trades and the resulting price is similar to that examined in Section 3.1.

The general case also helps us to better understand the nature of the Walrasian equilibrium in our setting. For simplicity, let us set $b_{I}=0$. In the simple case considered in previous sections, we saw two different situations in states in which I-investors end up holding zero shares in equilibrium (i.e., when $S \leq z^{*}$ ). For $z<S \leq z^{*}$, the equilibrium price remains informative about $S$; while for $S \leq z$, which we call uninformative states, the equilibrium price becomes uninformative. This equilibrium requires that I-investors submit a demand dependent on $S$ in the informative states, knowing that they will end up with zero shares in equilibrium. This might seem puzzling when I-investors know for sure when the economy is in these states (they should instead submit a zero demand). This is no longer the case when U-investors also face shock $X_{U}$. Since I-investors do not directly observe $X_{U}$, they do not know ex ante whether their holdings will be zero in equilibrium or not. Thus, they will submit their full demand, despite the possibility of ex post holding zero shares in equilibrium (as long as it is not for sure).

However, it is worth pointing out that there remain states in which the I-investors know ex ante that their holding will be zero for sure. To see this, let $\underline{z}$ denote the lower bound of $z\left(X_{U}\right)$, i.e., $\underline{z}=z\left(a_{U}\right)$. For $a_{U}<x_{1}$, where $x_{1}$ is given in (35), we have

$$
\underline{z}=-a_{F}-\left(3 / \widehat{\theta}_{U}\right)\left[1-\sqrt{1+\frac{1}{2} \sigma_{u N} \widehat{\theta}_{U}\left(x_{1}-a_{U}\right)}\right]
$$


and $-a_{F}<\underline{z} \leq z\left(X_{U}\right)$. When $S \leq \underline{z}$, the I-investors know that their holding will be zero no matter what the realization of $X_{U}$ is. For these states, they will simply submit a zero demand (for all feasible prices), independent of $S$. The existence of these states provide the economic justification for non-informative states. ${ }^{15}$ For $S>\underline{z}$, the I-investors will submit their demand full demand, which depends on $S$ and $P$. What is interesting is that the uninformative states are not limited to $-a_{F} \leq S \leq \underline{z}$, but also include those with $\underline{z}<S \leq z\left(X_{U}\right)$. This arises from the market clearing condition. As discussed in Section 4, the equilibrium price drops discretely in the uninformative states as the U-investors' perception of the mean and variance of stock payoff changes. The set of uninformative states have to be such that when the price drops, the I-investors' equilibrium holding remains at zero (i.e., market clears). It is this condition that determines $z\left(X_{U}\right)$ (not $\left.\underline{z}\right)$ as the boundary of uninformative states. For $z\left(X_{U}\right)<S \leq z^{*}\left(X_{U}\right)$, the equilibrium price becomes informative, despite the fact that the I-investors will stay at zero holdings in equilibrium. This is feasible since the I-investors' demand is present in the market and also utilized in order for the market to clear. For $S>z^{*}\left(X_{U}\right)$, we have the more typical situation in which both I- and U-investors obtain positive stock holdings in equilibrium.

\section{Conclusion}

In this paper, we present a rational expectations equilibrium model with heterogeneously informed investors to analyze the impact of short-sale constraints on asset prices. We show that constraining short sales reduces market's allocational and informational efficiency by limiting trades for risk-sharing and private information. However, these two effects drive market prices in opposite directions. Limiting trades for risk sharing effectively increases the total asset demand. This has the effect of increasing asset price and decrease its volatility. Limiting trades for private information reduces the informativeness of market prices and raises the risk as perceived by less informed investors. This has the effect of decreasing asset price and increase its volatility. We show that when the information effect is significant, shortsale constraint can actually cause prices to decrease and to be more volatile. These results shed new lights on the growing empirical evidence on the impact of short-sale constraints. Moreover, we show that short-sale constraints can give rise to market crashes. Crashes occur in our model when better informed investors are held out from the market and prices cease

\footnotetext{
${ }^{15} \mathrm{By}$ assuming that investors submit a zero demand if they know for sure that their holding will be zero, we have also ruled out other possible equilibria, which require them to submit full demand and thus make available their private information, even in this situation. This type of equilibria, although mathematically valid if they exist, are hard to justify and to implement economically.
} 
to be informative. In this situation, the risk as perceived by less informed investors in the market surges, causing price to fall discretely. Such a price fall in our model is accompanied with no big news, a jump in perceived uncertainty and an increase in price volatility. These characteristics resembles observed stock market crashes. 


\section{References}

[1] Allen F., S. Morris, and A. Postlewaite, 1993, Finite Bubbles with Short Sale Constraints and Asymmetric Information, Journal of Economic Theory 61, 206-229.

[2] Almazan, A., M. Carlson, C. B. Keith, and D. A. Chapman, 2003, Why Constrain Your Mutual Fund Manager?, Journal of Financial Economics, forthcoming.

[3] Altken M. J., A. Frino, M S. McCorry and P. L. Swan, 1998, Short Sales Are Almost Instantaneously Bad News: Evidence from the Australian Stock Exchange, Journal of Finance 53, 2205-2223.

[4] Asquith, P., P. A. Pathak and J. R. Ritter, 2005, Short Interest, Institutional Ownership, and Stock Returns, Journal of Financial Economics, 78(2), 243-276.

[5] Battalio R., and P. Schultz, 2005, Options and the Bubble, Journal of Finance, forthcoming.

[6] Black, F., 1976, Studies in Stock Price Volatility Changes, Proceedings of the 1976 Business Meeting of the Business and Economic Statistics Section, American Statistical Association, 177-181.

[7] Boehme, R. D., B. R. Danielsen, and S. M. Sorescu, 2005, Short Sale Constraints, Differences of Opinion, and Overvaluation, Journal of Financial and Quantitative Analysis, forthcoming.

[8] Bris, A., W. N. Goetzmann, and N. Zhu, 2004, Efficiency and the Bear: Short Sales and Markets around the World, working paper, Yale University.

[9] Chang, E. C., J. W. Cheng, and Y. Yu, 2006, Short-Sales Constraints and Price Discovery: Evidence from the Hong Kong Market, Journal of Finance, forthcoming.

[10] Cao, H. and H. Zhang, 2002, Short-Sale Constraint, Informational Efficiency and Price Bias, working paper.

[11] Charoenrook, A. and H. Daouk, A Study of Market-Wide Short-Selling Restrictions, 2005, working paper.

[12] Chen, J., H. Hong and J. Stein, Forecasting Crashes: Trading Volume, Past Returns, and Conditional Skewness in Stock Prices, 2001, Journal of Financial Economics 61, 345-381.

[13] Chen, J., H. Hong, and J. Stein, 2002, Breadth of Ownership and Stock Returns, Journal of Financial Economics 66, 171-205.

[14] Christie, A. A., 1982, The Stochastic Behavior of Common Stock Variances: Value, Leverage and Interest Rate Effects, Journal of Financial Economics, 10, 407-432. 
[15] Conrad, J., 1989, The Price Effect of Option Introduction, Journal of Finance, 44, 487498.

[16] Danielsen, B. R. and S. M. Sorescu, 2001, Why Do Option Introductions Depress Stock Prices? A Study of Diminishing Short Sale Constraints, Journal of Financial and Quantitative Analysis 36, 451-484.

[17] D'Avolio, G., 2002, The Market for Borrowing Stock, Journal of Financial Economics 66, 271-306.

[18] Dechow, P., A. Hutton, L. Meulbroek, and R. Sloan, 2001, Short-Sellers, Fundamental Analysis and Stock Returns, Journal of Financial Economics 61, 77-106.

[19] Detemple, J. and S. Murthy, 1994, Intertemporal Asset Pricing with Heterogeneous Beliefs, Journal of Economic Theory 62, 294-320.

[20] Diamond, D. W. and R. E. Verrecchia, 1987, Constraints on Short-Selling and Asset Price Adjustment to Private Information, Journal of Financial Economics 18, 277-311.

[21] Duffie D., N. Garleanu, L. H. Pedersen, 2002, Securities Lending, Shorting, and Pricing, Journal of Financial Economics 66, 307-339.

[22] Dumas, B., 1989, Two-Person Dynamic Equilibrium in the Capital Market, Review of Financial Studies, 2, 157-188.

[23] Figlewski, S., 1981, The Informational Effects of Restrictions on Short Sales: Some Empirical Evidence, Journal of Financial and Quantitative Analysis 4, 463-476.

[24] Figlewski, S. and G. P. Webb, 1993, Options, Short Sales, and Market Completeness, Journal of Finance 48, 761-777.

[25] French, K. R., G. W. Schwert, and R. F. Stambaugh, 1987, Expected Stock Returns and Volatility, Journal of Financial Economics 19, 3-29.

[26] Geczy C. C., D. K. Musto and A. V. Reed, 2002, Stocks Are Special Too: An Analysis of the Equity Lending Market, Journal of Financial Economics 66, 241-269.

[27] Grossman, S. J., and J. Stiglitz, 1980, On the Impossibility of Informationally Efficient Markets, American Economic Review 70, 393-408.

[28] Gulen, H., and S. Mayhew, 2000, Stock Index Futures Trading and Volatility in International Equity Markets, Journal of Futures Markets 20, 661-685.

[29] Harris, M. and A. Raviv, 1993, Differences of Opinion Make A Horse Race, Review of Financial Studies 6(3), 473-506.

[30] Harrison, J. M. and D. M. Kreps, 1978, Speculative Investor Behavior in a Stock Market with Heterogeneous Expectations, Quarterly Journal of Economics 92, 323-336. 
[31] Hong, H. and J. C. Stein, 2003, Difference of Opinion, Short-Sales Constraints and Market Crashes, Review of Financial Studies 16(2), 487-525.

[32] Jarrow, R., 1980, Heterogeneous Expectations, Restrictions on Short Sales, and Equilibrium Asset Prices, Journal of Finance 35, 1105-1113.

[33] Jones, M. C., and O. A. Lamont, 2002, Short-Sale Constraints and Stock Returns, Journal of Financial Economics 66(2-3), 207-239.

[34] Krishnamurthy, A., 2002, The Bond/Old-Bond Spread, Journal of Financial Economics 66, 463-506.

[35] Lamont, O. A. and J. C. Stein, 2004, Aggregate Short Interest and Market Valuations, American Economic Review 94(2), 29-32.

[36] Mayhew, S., and V. Mihov, 2005, Short Sale Constraints, Overvaluation and the Introduction of Options, working paper.

[37] Miller, E., 1977, Risk, Uncertainty, and Divergence of Opinion, Journal of Finance 32, 1151-1168.

[38] Nagel, S., 2005, Short Sales, Institutional Investors and the Cross-Section of Stock Returns, Journal of Financial Economics, 78(2), 277-309.

[39] Ofek, E. and M. Richardson, 2003, DotCom Mania: The Rise and Fall of Internet Stock Prices, Journal of Finance 58, 1113-1137.

[40] O'Hara, M., 2003, Liquidity and price discovery, Journal of Finance 58, 1335-1354.

[41] Reed, A. V., 2003, Costly Short-Selling and Stock Price Adjustment to Earnings Announcements, working paper.

[42] Rubinstein, M. E., 2004, Great Moments in Financial Economics: III. Short-Sales and Stock Prices, Journal of Investment Management 2.

[43] Scheinkman, J. and W. Xiong, 2003, Overconfidence and Speculative Bubbles, Journal of Political Economy 111, 1183-1219.

[44] Securities and Exchange Commission, 1999, SEC Concept Release: Short Sales.

[45] Senchack, A. J. and L. Starks, 1993, Short Sale Restrictions and Market Reactions to Short-Interest Announcements, Journal of Financial and Quantitative Analysis 28, 177194.

[46] Seneca, J. J., 1967, Short Interest: Bearish or Bullish?, Journal of Finance 22, 67-70.

[47] Wang, J., 1993, A Model of Intertemporal Asset Prices Under Asymmetric Information, Review of Economic Studies 60, 249-282. 
[48] Wang, J., 1994, A Model of Competitive Stock Trading Volume, Journal of Political Economy 102, 127-168.

[49] Wang, J., 1996, The Term Structure of Interest Rates In A Pure Exchange Economy With Heterogeneous Investors, Journal of Financial Economics 41, 75-110.

[50] Yuan, K., 2004, Securities Trading Under Asymmetric Information and Trading Constraints, working paper, University of Michigan. 


\section{Appendix}

Here we provide the proofs to the lemmas, propositions and corollaries in the paper. Since the solution to the most general case in the paper is given in Section 5, we will prove the results there which will lead to the results in the prior sections as special cases.

Proof of Lemma 1. Investor $i$ 's utility is given by

$$
\begin{aligned}
U_{i}\left(W_{i}\right) & =\mathrm{E}\left[W_{i} \mid \mathcal{I}_{i}\right]-\frac{1}{2} \operatorname{Var}\left[W_{i} \mid \mathcal{I}_{i}\right] \\
& =\bar{\theta} P+\theta_{i}\left(\mathrm{E}\left[F \mid \mathcal{I}_{i}\right]-P\right)+X_{i} \mu_{N}-\frac{1}{2} \theta_{i}^{2}\left(\operatorname{Var}\left[F \mid \mathcal{I}_{i}\right]+\sigma_{u}^{2}\right)-\theta_{i} X_{i} \sigma_{u N}-\frac{1}{2} X_{i}^{2} \sigma_{N}^{2}
\end{aligned}
$$

Solving the first order condition $\frac{\partial U_{i}}{\partial \theta_{i}}=0$ without short-sale constraints, we have

$$
\theta_{i}=\frac{\left(\mathrm{E}\left[F \mid \mathcal{I}_{i}\right]-P\right)-\sigma_{u N} X_{i}}{\operatorname{Var}\left[F \mid \mathcal{I}_{i}\right]+\sigma_{u}^{2}}
$$

Imposing short-sale constraints, we have the solution to optimal stock demand for investor $i$ as given in Lemma 1.

Proof of Proposition 1. Substituting $\mathrm{E}\left[F \mid \mathcal{I}_{i}\right]=F, \operatorname{Var}\left[F \mid \mathcal{I}_{i}\right]=0, b_{i}=\infty, i=I, U$ and $\sigma_{U}=0$ into Lemma 1 , we have $\theta_{I}=\left(F-P-\sigma_{u N} X_{I}\right) / \sigma_{u}^{2}, \theta_{U}=(F-P) / \sigma_{u}^{2}$. Substituting them into the market-clear condition (7), we have

$$
P^{*}=F-w \sigma_{u N} X_{I}-\sigma_{u}^{2} \bar{\theta}
$$

Similarly, letting $b_{I}=0$ and $b_{U}=\infty$ into Lemma 1 , we have $\theta_{I}=\max \left[\left(F-P-\sigma_{u N} X_{I}\right) / \sigma_{u}^{2}, 0\right]$ and $\theta_{U}=(F-P) / \sigma_{u}^{2}$. Substituting them into the market-clear condition (7), we have

$$
P= \begin{cases}F-w \sigma_{u N} X_{I}-\sigma_{u}^{2} \bar{\theta}, & X_{I} \leq \widehat{\theta} / h \\ F-\sigma_{u}^{2} \widehat{\theta}, & X_{I}>\widehat{\theta} / h\end{cases}
$$

where $\widehat{\theta}=\bar{\theta} /(1-w)$. Clearly, $P \leq P^{*}$.

Proof of Lemmas 2 and 4. We prove Lemma 4, which has Lemma 2 as a special case. Let $Y=\sigma_{u N} X_{I}$. Then, $S=\frac{1}{2}(F-Y)$ and $S \in\left[-a_{F}, a_{F}\right]$. Let $f_{F}(\cdot)$ and $f_{Y}(\cdot)$ denote the probability density function of $F$ and $Y$, respectively. Thus, $f_{F}(F)=\frac{1}{2 a_{F}} 1_{\left[-a_{F}, a_{F}\right]}(F)$ and $f_{Y}(Y)=\frac{1}{2 a_{F}} 1_{\left[-a_{F}, a_{F}\right]}(Y)$. Since, $F$ and $Y$ are independent, the joint probability density function for $F$ and $Y$ is simply $f_{F, Y}(F, Y)=f_{F}(F) f_{Y}(Y)$. From Conjecture 2, when $P>\widehat{p}$ 
we have $f(F \mid P)=f(F \mid S)$ and

$$
\begin{aligned}
f(F \mid S)=\frac{f_{F}(F) f_{Y}(F-2 S)}{\int_{-a_{F}}^{a_{F}} f_{F}(F) f_{Y}(F-2 S) d F} & =\frac{1}{2\left(a_{F}-|S|\right)} 1_{\left[-a_{F}, a_{F}\right]}(F) 1_{\left[-a_{F}, a_{F}\right]}(F-2 S) \\
& = \begin{cases}\frac{1}{2\left(a_{F}-|S|\right)} 1_{\left[-a_{F}+2 S, a_{F}\right]}(F) & S \geq 0 \\
\frac{1}{2\left(a_{F}-|S|\right)} 1_{\left[-a_{F}, a_{F}+2 S\right]}(F) & S<0 .\end{cases}
\end{aligned}
$$

It follows that $\mathrm{E}[F \mid S]=\int F f(F \mid S) d F=S$ and $\operatorname{Var}[F \mid S]=\int(F)^{2} f(F \mid S) d F-\mathrm{E}^{2}[F \mid S]=$ $\frac{1}{3}\left(a_{F}-|S|\right)^{2}$. This proves Lemma 2. When $P \leq \widehat{p}, S \leq z<0$. Thus, $f(F \mid P)=f(F \mid S \leq z)$ and with $z<0$ we have

$$
f(F \mid S \leq z)=\frac{\int_{-a_{F}}^{z} f_{F}(F) f_{Y}(F-2 S) d S}{\int_{-a_{F} \leq F-Y \leq 2 z} f_{F}(F) f_{Y}(Y) d F d Y}=\frac{a_{F}+2 z-F}{2\left(z+a_{F}\right)^{2}} 1_{\left[-a_{F}, 2 z+a_{F}\right]}(F) .
$$

Then, $\mathrm{E}[F \mid P \leq \widehat{p}]=\int F f(F \mid S \leq z) d F=\frac{1}{3}\left(2 z-a_{F}\right), \operatorname{Var}[F \mid P \leq \widehat{p}]=\int(F)^{2} f(F \mid S \leq z) d F-$ $\mathrm{E}^{2}[F \mid S \leq z]=\frac{2}{9}\left(z+a_{F}\right)^{2}$.

Proof of Lemmas 3, 5 and 6. Substituting (15) into Lemma 1, Lemma 6 is immediate. Let $\sigma_{U}=0$ and $b_{U}=\infty$, we obtain Lemma 5. Let $\sigma_{U}=0$ and $b_{U}=b_{I}=\infty$, we have $\widehat{z}\left(X_{U}\right)=a_{F}$ and Lemma 3.

Proof of Propositions 2, 3 and 9. We prove Proposition 9. Propositions 2 and 3 will follow as special cases. We need to show that there is a solution to the price in the market clearing condition (7) of the form in Conjecture 3. As stated in the conjecture, given $X_{U}$ the price is a function of $S$, with different properties over its range. The difference in the behavior of the price function arises from the short-sale constraints investors face in different states. We start our proof by finding different ranges of $S$ over which the price behaves differently.

(i) When U-investors' holding reaches its lower bound $-b_{U}$, we have

$$
\theta_{I}=(2 S-P) / \sigma_{u}^{2}=\widehat{\theta}_{I}, \quad \theta_{U}=\frac{S-P-\sigma_{u N} X_{U}}{\sigma_{u}^{2}+\frac{1}{3}\left(a_{F}-|S|\right)^{2}}=-b_{U} .
$$

Solving for $S$, we obtain its critical value $\widehat{z}\left(X_{U}\right)$ as given in (36). Thus, for $S>\widehat{z}\left(X_{U}\right)$, U-investors are constrained.

(ii) Even when I-investors' equilibrium holding hits its lower bound $-b_{I}$, the equilibrium price can remain informative about $S$ as I-investors' demand in general depends on $S$. In this case, we have

$$
\theta_{I}=(2 S-P) / \sigma_{u}^{2}=-b_{I}, \quad \theta_{U}=\frac{S-P-\sigma_{u N} X_{U}}{\sigma_{u}^{2}+\frac{1}{3}\left(a_{F}-|S|\right)^{2}}=\widehat{\theta}_{U}
$$

Solving for $S$, we obtain the critical value $z^{*}\left(X_{U}\right)$ as given in (36). 
(iii) When I-investors' equilibrium holding remains at its lower bound $-b_{I}$ and the equilibrium price fails to be informative, we have

$$
\theta_{I}=-b_{I}, \quad \theta_{U}=\frac{\frac{1}{3}\left[2 z\left(X_{U}\right)-a_{F}\right]-P-\sigma_{u N} X_{U}}{\sigma_{u}^{2}+\frac{2}{9}\left[z\left(X_{U}\right)+a_{F}\right]^{2}}=\widehat{\theta}_{U} .
$$

Note that in this case, U-investors' holding does not depend on $S$ as the equilibrium price no longer reveals it. Solving for $S$, we obtain the critical value $z\left(X_{U}\right)$ as given in (36). Thus, for $S \leq z\left(X_{U}\right)$, the market price becomes merely a function of $X_{U}$, independent of $S$.

Next, we prove that given $X_{U}$ the whole range of $S$ is divided into four intervals by $\widehat{z}, z^{*}$ and $z$. First, let

$$
k\left(X_{U}\right)= \begin{cases}\sigma_{u N} \widehat{\theta}_{U}\left(x_{1}-X_{U}\right), & X_{U}<x_{1} \\ 0, & X_{U} \geq x_{1}\end{cases}
$$

Since $k\left(X_{U}\right) \geq 0$, from condition (4) we have

$$
z\left(X_{U}\right)=-a_{F}-3\left(\widehat{\theta}_{U}\right)^{-1}\left[1-\sqrt{1+\frac{1}{2} k\left(X_{U}\right)}\right] \leq-a_{F}-\frac{3}{4}\left(\widehat{\theta}_{U}\right)^{-1} k\left(X_{U}\right) \leq 0
$$

Moreover,

$$
k\left(X_{U}\right)<\frac{\left(a_{F}-\sigma_{u N} X_{U}-b_{I} \sigma_{u}^{2}\right)^{2}}{4 \sigma_{u}^{2}} \leq \frac{\left(\frac{4}{3} a_{F}\right)^{2}}{4 \sigma_{u}^{2}} \leq \frac{4}{3} .
$$

It is easy to show that

$$
z^{*}\left(X_{U}\right)+a_{F}=\frac{\left(2 / \widehat{\theta}_{U}\right) k\left(X_{U}\right)}{1+\sqrt{1+\frac{4}{3} k\left(X_{U}\right)}} \geq \frac{\left(\frac{3}{2} / \widehat{\theta}_{U}\right) k\left(X_{U}\right)}{1+\sqrt{1+\frac{1}{2} k\left(X_{U}\right)}}=z\left(X_{U}\right)+a_{F}
$$

From their definitions, we have

$$
\begin{gathered}
z^{*}\left(X_{U}\right) \begin{cases}<a_{F}+\sigma_{u N}\left(x_{1}-X_{U}-2 a_{F} / \sigma_{u N}\right)=-\sigma_{u N} X_{U}, & X_{U}<x_{2} \\
<-a_{F}+\sigma_{u N}\left(x_{1}-X_{U}\right)=-\sigma_{u N} X_{U}, & x_{2} \leq X_{U}<x_{1} \\
=-a_{F}<-\sigma_{u N} X_{U}, & X_{U} \geq x_{1}\end{cases} \\
\widehat{z}\left(X_{U}\right) \begin{cases}=a_{F}>-\sigma_{u N} X_{U}, & X_{U} \leq x_{3} \\
>a_{F}-\sigma_{u N}\left(X_{U}-x_{3}\right)=-\sigma_{u N} X_{U}, & x_{3}<X_{U} \leq x_{4} \\
>-a_{F}-\sigma_{u N}\left(X_{U}-x_{3}-2 a_{F} / \sigma_{u N}\right)=-\sigma_{u N} X_{U}, & X_{U}>x_{4}\end{cases}
\end{gathered}
$$

Thus, $\widehat{z}\left(X_{U}\right) \geq-\sigma_{u N} X_{U} \geq z^{*}\left(X_{U}\right) \geq z\left(X_{U}\right)$.

Now we only need to consider the above four intervals of $S$, find the corresponding market clearing price and confirm that it satisfies the monotonicity properties in Conjecture 3. Given 
investors' optimal stock demand in (32) and (33) and the market-clearing condition (7), we can easily compute the market clearing price $P$ :

(i) For $S>\widehat{z}\left(X_{U}\right), \theta_{U}=-b_{U}$ and we have $P=2 S-\sigma_{u}^{2} \widehat{\theta}_{I}$.

(ii) For $z^{*}\left(X_{U}\right)<S \leq \widehat{z}\left(X_{U}\right)$, both I- and U-investors are unconstrained. From (32), (33) and $(7)$, we obtain the market clearing price in (37).

(iii) For $z\left(X_{U}\right)<S \leq z^{*}\left(X_{U}\right), \theta_{I}=-b_{I}$ but the equilibrium price remains informative (about $S$ ). Since in these states U-investors are the marginal investors, from their demand in (A.2) and the market clearing condition, we have $P=S-\left[\sigma_{u}^{2}+\frac{1}{3}\left(a_{F}-|S|\right)^{2}\right] \widehat{\theta}_{U}-\sigma_{u N} X_{U}$.

(iv) For $S \leq z\left(X_{U}\right), \theta_{I}=-b_{I}$ and the equilibrium price fails to be informative to Uinvestors. Again, U-investors are the marginal investors; from their demand in (A.3) and the market clearing condition, we have $P=2 z\left(X_{U}\right)+\sigma_{u}^{2} b_{I}$, which is indeed independent of $S$.

Finally, we verify that given $X_{U}, P$ is monotonic in $S$ for $S>z\left(X_{U}\right)$ in order to confirm Conjecture 3.

(a) When $S>\widehat{z}\left(X_{U}\right)$,

$$
\frac{\partial p}{\partial S}=2>0
$$

(b) When $z^{*}\left(X_{U}\right)<S \leq \widehat{z}\left(X_{U}\right)$ and $S>0$,

$$
\begin{aligned}
\frac{\partial P}{\partial S} & =2-\frac{\sigma_{u}^{2}(1-w)}{\left[\sigma_{u}^{2}+\frac{1}{3} w\left(a_{F}-S\right)^{2}\right]^{2}}\left[\sigma_{u}^{2}+\frac{1}{3} w\left(a_{F}-S\right)\left(a_{F}+S-2 \frac{\bar{\theta}}{w} \sigma_{u}^{2}+2 \sigma_{u N} X_{U}\right)\right] \\
& >2-\frac{1-w}{\sigma_{u}^{2}}\left(\sigma_{u}^{2}+\frac{2}{3} w a_{F}^{2}\right)>2-(1-w)(1+2 w)=(1-w)+2 w^{2}>0 .
\end{aligned}
$$

(c) When $z^{*}\left(X_{U}\right)<S \leq \widehat{z}\left(X_{U}\right)$ and $S<0$,

$$
\begin{aligned}
\frac{\partial P}{\partial S} & =2-\frac{\sigma_{u}^{2}(1-w)}{\left[\sigma_{u}^{2}+\frac{1}{3} w\left(a_{F}+S\right)^{2}\right]^{2}}\left[\sigma_{u}^{2}+\frac{1}{3} w\left(a_{F}+S\right)\left(a_{F}-S+2 \frac{\bar{\theta}}{w} \sigma_{u}^{2}-2 \sigma_{u N} X_{U}\right)\right] \\
& >2-\frac{1-w}{\sigma_{u}^{2}}\left(\sigma_{u}^{2}+\frac{2}{3} w a_{F}^{2}\right)>2-(1-w)(1+2 w)=(1-w)+2 w^{2}>0 .
\end{aligned}
$$

(d) When $z\left(X_{U}\right)<S \leq z^{*}\left(X_{U}\right)$ and $S>0$,

$$
\begin{aligned}
\frac{\partial P}{\partial S} & =1-\frac{2}{3} \widehat{\theta}_{U}\left(S-a_{F}\right) \\
& \geq 1-\frac{2}{3} \widehat{\theta}_{U}\left(a_{F}-\sigma_{u N} a_{U}\right) \geq 1+\frac{4}{9} \widehat{\theta}_{U} a_{F}>0 .
\end{aligned}
$$

(e) When $z\left(X_{U}\right)<S \leq z^{*}\left(X_{U}\right)$ and $S<0$,

$$
\begin{aligned}
\frac{\partial P}{\partial S} & =1-\frac{2}{3} \widehat{\theta}_{U}\left(S+a_{F}\right) \\
& \left.\geq 1-\frac{2}{3} \widehat{\theta}_{U}\left[z^{*}\left(X_{U}\right)+a_{F}\right]=2-\sqrt{1+\frac{4}{3} \widehat{\theta}_{U}\left[a_{F}-\sigma_{u}^{2}\left(\widehat{\theta}_{U}+b_{I}\right)-\sigma_{u N} X_{U}\right.}\right] \\
& \geq 2-\left(\sigma_{u}\right)^{-1} \sqrt{\sigma_{u}^{2}+\frac{1}{3}\left(a_{F}-\sigma_{u N} X_{U}-\sigma_{u}^{2} b_{I}\right)^{2}} \geq 2-\sqrt{1+\left(\frac{4}{3}\right)^{2} \sigma_{F}^{2} / \sigma_{u}^{2}} \geq 2-\frac{5}{3}>0 .
\end{aligned}
$$


This completes the proof of Proposition 9. Let $\sigma_{U}=0$ and $b_{U}=\infty$, we obtain Proposition 3. Let $\sigma_{U}=0, b_{U}=\infty$, and $b_{U}=\infty$, we have $\widehat{z}=a_{F}$ and Proposition 2 .

Proof of Corollary 1. The results on equilibrium stock holdings are immediate. We only need to prove their monotonicity in $S$. When $S<0$, it is easy to show that $\frac{\partial \theta_{I}}{\partial S}>0$. When $S>0$,

$$
\frac{\partial \theta_{I}}{\partial S}=\frac{\sigma_{u}^{2}+\frac{1}{3}\left(a_{F}-S\right)\left[w\left(a_{F}-\frac{1}{3} S\right)-\frac{2}{3} \sigma_{u}^{2} \bar{\theta}\right]}{\left[\sigma_{u}^{2}+\frac{1}{3} w\left(a_{F}-S\right)^{2}\right]^{2}}>\frac{\sigma_{u}^{2}+\frac{1}{3} a_{F}\left(-\frac{2}{3} \sigma_{u}^{2} \bar{\theta}\right)}{\left[\sigma_{u}^{2}+\frac{1}{3} w\left(a_{F}-S\right)^{2}\right]^{2}}>\frac{\sigma_{u}^{2}-\frac{2}{3} \sigma_{F}^{2}}{\left[\sigma_{u}^{2}+\frac{1}{3} w\left(a_{F}-S\right)^{2}\right]^{2}}>0 .
$$

Clearly, $\frac{\partial \theta_{U}}{\partial S}=-\frac{w}{1-w} \frac{\partial \theta_{I}}{\partial S}<0$.

Proof of Proposition 4. From Lemmas 2 and 4, we have:

$$
\begin{aligned}
\mathrm{E}\left[\mathrm{E}\left[F \mid P^{*}\right] \mid \Omega_{B}\right] & =\frac{\int_{-a_{F}}^{z} \mathrm{E}\left[F \mid P^{*}\right] f_{S}(S) d S}{\int_{-a_{F}}^{z} f_{S}(S) d S}=\frac{\int_{-a_{F}}^{z} S \frac{a_{F}-|S|}{a_{F}^{2}} d S}{\int_{-a_{F}}^{z} \frac{a_{F}-|S|}{a_{F}^{2}} d S}=\frac{1}{3}\left(2 z-a_{F}\right)=\mathrm{E}\left[\mathrm{E}[F \mid P] \mid \Omega_{B}\right] \\
\mathrm{E}\left[\operatorname{Var}\left[F \mid P^{*}\right] \mid \Omega_{B}\right] & =\frac{\int_{-a_{F}}^{z} \operatorname{Var}\left[F \mid P^{*}\right] f_{S}(S) \mathrm{d} S}{\int_{-a_{F}}^{z} f_{S}(S) \mathrm{d} S}=\frac{\int_{-a_{F}}^{z} \frac{1}{3}\left(a_{F}-|S|\right)^{2} \cdot \frac{a_{F}-|S|}{a_{F}^{2}} \mathrm{~d} S}{\int_{-a_{F}}^{z} \frac{a_{F}-|S|}{a_{F}^{2}} \mathrm{~d} S}=\frac{\left(z+a_{F}\right)^{2}}{6} \\
& <\frac{2\left(z+a_{F}\right)^{2}}{9}=\operatorname{Var}\left[\mathrm{E}[F \mid P] \mid \Omega_{B}\right] .
\end{aligned}
$$

Proof of Proposition 5. Using the result of Propositions 2 and 3, the expected stock price change due to short-sale constraints is given by

$$
\begin{aligned}
\mathrm{E}\left[P-P^{*}\right]= & \frac{\sigma_{u}^{2}}{w a_{F}}\left\{3(1-w)\left(z^{*}+a_{F}\right)+\frac{1}{2} \bar{\theta}\left(z^{*}+a_{F}\right)^{2}-3(1-w) \sqrt{\frac{w}{3}} \arctan \left(\sqrt{\frac{w}{3}} \frac{z^{*}+a_{F}}{\sigma_{u}}\right)\right. \\
& \left.-\frac{3}{2}(1-w)\left(a_{F}+\frac{\sigma_{u}^{2} \bar{\theta}}{w}\right) \ln \left[1+\frac{w\left(z^{*}+a_{F}\right)^{2}}{3 \sigma_{u}^{2}}\right]\right\}+\frac{1}{a_{F}^{2}}\left\{\frac{\bar{\theta}}{12(1-w)}\left[\left(z+a_{F}\right)^{4}-\left(z^{*}+a_{F}\right)^{4}\right]\right. \\
& \left.+\frac{1}{3}\left[\left(z+a_{F}\right)^{3}-\left(z^{*}+a_{F}\right)^{3}\right]+\frac{1}{2}\left(\frac{\sigma_{u}^{2} \bar{\theta}}{1-w}-a_{F}\right)\left[\left(z+a_{F}\right)^{2}-\left(z^{*}+a_{F}\right)^{2}\right]\right\} .
\end{aligned}
$$

Thus, $\mathrm{E}\left[P-P^{*}\right]$ is a continuous function of $w$. Let us consider the extreme situation that $w \rightarrow 0$. In this case, we have

$$
P^{*}=S-\left[\sigma_{u}^{2}+\frac{1}{3}\left(a_{F}-|S|\right)^{2}\right] \bar{\theta} ; \quad P= \begin{cases}S-\left[\sigma_{u}^{2}+\frac{1}{3}\left(a_{F}-|S|\right)^{2}\right] \bar{\theta}, & S>z \\ 2 z, & S \leq z\end{cases}
$$

where $z=-a_{F}+3 \bar{\theta}^{-1}\left(\sqrt{1+\frac{1}{2} a_{F} \bar{\theta}-\frac{1}{2} \sigma_{u}^{2} \bar{\theta}^{2}}-1\right)$. And

$$
\begin{aligned}
\mathrm{E}\left[P-P^{*}\right] & =\int_{-a_{F}}^{z}\left\{2 z-S+\left[\sigma_{u}^{2}+\frac{1}{3}\left(a_{F}-|S|\right)^{2}\right] \bar{\theta}\right\} \frac{a_{F}-|S|}{a_{F}^{2}} d S \\
& =\frac{\sqrt{1+\frac{1}{2} \bar{\theta}\left(a_{F}-\sigma_{u}^{2} \bar{\theta}\right)}-1}{2 \bar{\theta}}-\frac{a_{F}-\sigma_{u}^{2} \bar{\theta}}{8}=-\frac{\bar{\theta}\left(z+a_{F}\right)^{4}}{36 a_{F}^{2}} \leq 0
\end{aligned}
$$


which means there exists $0<\underline{w}<1$, for $w<\underline{w}, \mathrm{E}\left[P-P^{*}\right] \leq 0$.

Proof of Proposition 6. From (27) we have

$$
\begin{aligned}
\frac{\partial \mathrm{E}\left[P-P^{*}\right]}{\partial \sigma_{F}} & =-\frac{\sqrt{3} \bar{\theta}\left(z+a_{F}\right)^{3}}{18 a_{F}^{3} \sqrt{1+\frac{1}{2} \bar{\theta}\left(a_{F}-\sigma_{u}^{2} \bar{\theta}\right)}}\left\{\frac{3}{2} a_{F}-3 \bar{\theta}^{-1}\left[1+\frac{1}{2} \bar{\theta}\left(a_{F}-\sigma_{u}^{2} \bar{\theta}\right)-\sqrt{\left.\left.1+\frac{1}{2} \bar{\theta}\left(a_{F}-\sigma_{u}^{2} \bar{\theta}\right)\right]\right\}}\right.\right. \\
& <-\frac{\sqrt{3} \bar{\theta}\left(z+a_{F}\right)^{3}}{18 a_{F}^{3} \sqrt{1+\frac{1}{2} \bar{\theta}\left(a_{F}-\sigma_{u}^{2} \bar{\theta}\right.}}\left\{\frac{3}{2} a_{F}-3 \bar{\theta}^{-1} \cdot \frac{1}{2} \bar{\theta}\left(a_{F}-\sigma_{u}^{2} \bar{\theta}\right)\right\} \\
& =-\frac{\sqrt{3} \sigma_{u}^{2} \bar{\theta}^{2}\left(z+a_{F}\right)^{3}}{12 a_{F}^{3} \sqrt{1+\frac{1}{2} \bar{\theta}\left(a_{F}-\sigma_{u}^{2} \bar{\theta}\right)}}<0, \\
\frac{\partial \mathrm{E}\left[P-P^{*}\right]}{\partial \sigma_{u}} & =\frac{\sigma_{u} \bar{\theta}^{2}\left(z+a_{F}\right)^{3}}{6 a_{F} \sqrt{1+\frac{1}{2} \bar{\theta}\left(a_{F}-\sigma_{u}^{2} \bar{\theta}\right)}}>0 .
\end{aligned}
$$

Proof of Proposition 7. From (29a), (29b), and condition (11), we have

$$
\begin{aligned}
\operatorname{Var}[P] & =a_{F}^{2}+w^{2}\left[\frac{a_{F}^{2}}{6}+\frac{\left(\sigma_{u}^{2} \widehat{\theta}\right)^{2}}{2}-\frac{\left(\sigma_{u}^{2} \widehat{\theta}\right)^{3}}{3 a_{F}}-\frac{\left(a_{F}-\sigma_{u}^{2} \widehat{\theta}\right)^{2}}{4 a_{F}^{2}}\right] \\
& <a_{F}^{2}+w^{2}\left[\frac{1}{6} a_{F}^{2}+\frac{1}{2}\left(\sigma_{u}^{2} \widehat{\theta}\right)^{2}\right]<a_{F}^{2}+\frac{2}{3} w^{2} a_{F}^{2}<\left(1+w^{2}\right) a_{F}^{2}=\operatorname{Var}\left[P^{*}\right] .
\end{aligned}
$$

Proof of Proposition 8. From (31a), (31b), and condition (11), we have

$$
\begin{aligned}
\text { Skew }[P] & =\frac{w^{3}\left(a_{F}+\sigma_{u}^{2} \widehat{\theta}\right)^{4}}{2048 a_{F}^{5}}\left[\left(3 a_{F}-\sigma_{u}^{2} \widehat{\theta}\right)^{4}-\left(a_{F}+\sigma_{u}^{2} \widehat{\theta}\right)^{4}\right] \\
& =\frac{w^{3}\left(a_{F}+\sigma_{u}^{2} \widehat{\theta}\right)^{4}}{256 a_{F}^{4}}\left(a_{F}-\sigma_{u}^{2} \widehat{\theta}\right)\left[\left(3 a_{F}-\sigma_{u}^{2} \widehat{\theta}\right)^{2}+\left(a_{F}+\sigma_{u}^{2} \widehat{\theta}\right)^{2}\right] \geq 0=\operatorname{Skew}\left[P^{*}\right]
\end{aligned}
$$

